Document downloaded from:

http://hdl.handle.net/10251/141449

This paper must be cited as:

Viruela Navarro, A.; Robles Martínez, A.; Durán Pinzón, F.; Ruano García, MV.; Barat, R.; Ferrer, J.; Seco Torrecillas, A. (2018). Performance of an outdoor membrane photobioreactor for resource recovery from anaerobically treated sewage. Journal of Cleaner Production. 178:665-674. https://doi.org/10.1016/j.jclepro.2017.12.223

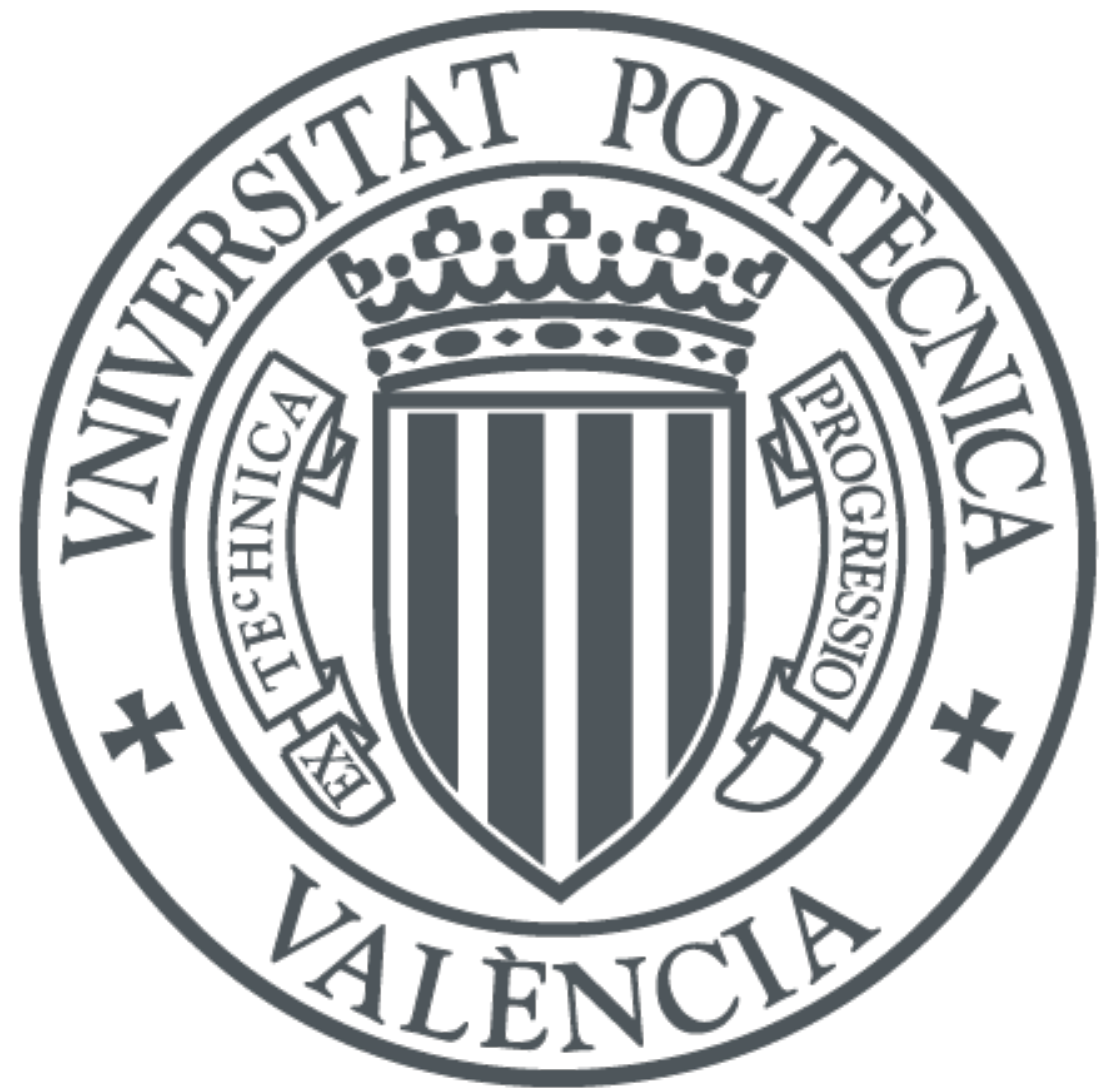

The final publication is available at

https://doi.org/10.1016/j.jclepro.2017.12.223

Copyright Elsevier

Additional Information 


\title{
Performance of an outdoor membrane photobioreactor for resource recovery from anaerobically treated sewage
}

\author{
Alexandre Viruela ${ }^{\mathrm{a}}$, Ángel Robles ${ }^{\mathrm{b},{ }^{*}}$, Freddy Durán ${ }^{\mathrm{a}}$, María Victoria Ruano ${ }^{\mathrm{b}}$, Ramón \\ Barat $^{\text {a }}$, José Ferrer ${ }^{\text {a }}$, Aurora Seco ${ }^{b}$ \\ a CALAGUA - Unidad Mixta UV-UPV, Institut Universitari d'Investigació d’Enginyeria de l’Aigua i \\ Medi Ambient - IIAMA, Universitat Politècnica de València, Camí de Vera s/n, 46022, València, Spain \\ (e-mail: alvina@upv.es, fredurpi@upv.es,rababa@dihma.upv.es,jferrer@hma.upv.es). \\ b CALAGUA - Unidad Mixta UV-UPV, Departament d'Enginyeria Química, ETSE-UV, Universitat de \\ València, Avinguda de la Universitat s/n, 46100, Burjassot, València, Spain (e-mail: angel.robles@uv.es; \\ m.victoria.ruano@uv.es; aurora.seco@uv.es) \\ * Corresponding author: angel.robles@uv.es
}

\begin{abstract}
The objective of this work was to evaluate the performance of a pilot scale membrane photobioreactor (MPBR) for treating the effluent of an anaerobic membrane bioreactor (AnMBR) system. In particular, new experimental data on microalgae productivity, nutrient recovery, $\mathrm{CO}_{2}$ biofixation and energy recovery potential was obtained under different operating conditions, which would facilitate moving towards cost-effective microalgae cultivation on wastewater. To this aim, a 2.2- $\mathrm{m}^{3} \mathrm{MPBR}$ equipped with two commercial-scale hollow-fibre ultrafiltration membrane modules was operated treating the nutrientloaded effluent from an AnMBR for sewage treatment. The influence of several design, environmental and operating parameters on MPBR performance was studied. Among the conditions evaluated, variations in solar irradiance significantly affected the nutrient recovery rate (NRR). Operating at temperatures above $25^{\circ} \mathrm{C}$ and high biomass concentrations, which increased light shading effect,
\end{abstract} negatively affected biomass production and NRR. Maximum biomass productivity of $66 \mathrm{mg} \mathrm{VSS} \cdot \mathrm{L}^{-1} \cdot \mathrm{d}^{-1}$ 
(areal productivity of $15.78 \mathrm{~g}$ VSS $\cdot \mathrm{m}^{-2} \cdot \mathrm{d}^{-1}$ ) and NRR of $7.68 \mathrm{mg} \mathrm{N} \cdot \mathrm{L}^{-1} \cdot \mathrm{d}^{-1}$ and $1.17 \mathrm{mg} \mathrm{P} \cdot \mathrm{L}^{-1} \cdot \mathrm{d}^{-1}$ were achieved when operating at 4.5 days of biomass retention time. These results would outcome maximum theoretical energy recoveries and $\mathrm{CO}_{2}$ biofixations of about $0.43 \mathrm{kWh}$ and $0.51 \mathrm{~kg} \mathrm{CO}_{2}$ per $\mathrm{m}^{3}$ of treated water, respectively. Moreover, the excellent quality permeate that was produced (i.e. negligible levels of pathogens and suspended solids) represents a reclaimed water source.

\section{Keywords}

Carbon dioxide capture; energy harvesting; membrane photobioreactor; microalgae cultivation; nutrient recovery; sewage treatment. 


\section{Introduction}

The application of new technologies for resource recovery from wastewater is normally conditioned by the necessity of including the water sector in the new development model focused on Circular Economy (Ghisellini et al., 2016). Wastewater treatment is an energy-intensive activity and it is highlighted in the Intergovernmental Panel on Climate Change (IPCC) guidelines (IPCC, 2006). Numerous studies (see e.g. FloresAlsina et al., 2011; Parravicini et al., 2016) can be found in the literature related to the estimation and minimisation of greenhouse gas (GHG) emissions in wastewater treatment plants (WWTPs), mainly focussed on the optimisation of plant design and/or operation (e.g. sludge retention time, dissolved oxygen level, or dosage of chemicals). Thus, the necessity of reducing the carbon footprint and other environmental impacts related to wastewater treatment is a key driving factor for shifting from the current WWTPs to water resource recovery facilities (WRRFs), which turns wastewater into a source of energy, nutrients and reclaimed water.

The recycle of the nutrients from wastewater to farmland, particularly phosphorus, is of great interest in Circular Economy since this component is an essential element irreplaceable in the production of crops and food (Ashley et al., 2011). In addition, nitrogen recovery from wastewater for agricultural purposes can help to reduce worldwide production costs due to the energy demand of fertiliser production (Do Nascimento et al., 2015).

Nutrient recovery from wastewater by means of microalgae-based processes is attracting interest from the scientific community (see e.g. Gao et al., 2015; Tsolcha et al., 2017). This interest is focused not only on moving towards WRRFs, but also on the 
possibility of offsetting the cost of fertilisers and the water needed to cultivate microalgae biomass. In addition, the carbon footprint is reduced by carbon dioxide biofixation (Mata et al., 2010), while harvesting solar energy in the form of algal biomass. This biomass is considered a high-value product since it can be converted, for instance, into fertilisers or into biogas through anaerobic digestion (see e.g. Jankowska et al., 2017).

However, one key technical limitation of microalgae cultivation during continuous operation is biomass washout. This washout can be easily overcome by the combination of microalgae cultivation and membrane filtration technology in the so-called membrane photobioreactor (MPBR), which enables decoupling both biomass retention time (BRT) and hydraulic retention time (HRT). Membrane technology allows the production of reclaimed water (i.e. negligible levels of pathogens and suspended solids can be reached when using, for instance, ultrafiltration membranes) from wastewater, which can be used for different purposes (e.g. irrigation, aquifer recharge, urban uses or industrial uses). However, further research is required in this field to ensure the feasibility of this technology (Bilad et al., 2014; Gao et al., 2014). MPBRs have some key issues that must be overcome such as high investment and maintenance costs and membrane fouling, among others. Additionally, outdoor performance of microalgae cultivation is significantly sensitive to the environmental and operating conditions. The available literature on microalgae cultivation in outdoor pilot-scale systems is limited (neither PBR nor MPBR). Systems of this type are necessary to evaluate the biomass productivity and nutrient recovery capacity of microalgae, elucidating issues of operation and establishing baselines for future cultivation improvement. 
Microalgae cultivation can growth on different wastewater-based mediums. For instance, Ruiz-Martinez et al. (2012) and Viruela et al. (2016) showed that the effluent from an anaerobic membrane bioreactor (AnMBR) fed with pre-treated sewage can be a suitable growth medium for microalgae cultivation in PBRs at lab scale and pilot scale, respectively. The combination of AnMBR and MPBR for sewage treatment results in a potentially sustainable treatment strategy. Microalgae cultivation allows nutrient uptake from wastewater while solar energy is harvested in the form of algal biomass, reducing the carbon footprint of wastewater treatment due to carbon dioxide biofixation. The generated algal biomass is a resource for fertiliser or biogas production, while the use of ultrafiltration membranes generates reclaimed water.

The objective of this work was to evaluate the performance of an outdoor pilot-scale MPBR for treating the effluent of an AnMBR system. In particular, new experimental data on microalgae productivity, nutrient recovery, $\mathrm{CO}_{2}$ biofixation and energy recovery potential was obtained under different operating conditions, which would facilitate moving towards cost-effective microalgae cultivation on wastewater. The pilot plant used in this study consists of an outdoor pilot-scale MPBR (working volume of $2.2 \mathrm{~m}^{3}$ ) equipped with industrial-scale membrane modules, which was fed with the effluent from an AnMBR plant (Giménez et al., 2011). The AnMBR system was fed with the effluent from the pre-treatment of the Carraixet WWTP (Valencia, Spain). In this work, MPBR performance was evaluated by studying the effects of different factors related to environmental and operating conditions (temperature, solar irradiance, BRT, nutrient loading rate and algal culture recirculation mode) and layout configuration (i.e. nonphotic volume fraction, ratio of membrane tank to PBR volume, taking into account that 
the membrane tank corresponds to non-photoactivated volume and the PBR corresponds to photoactivated volume).

\section{Material and methods}

\subsection{MPBR description}

The MPBR pilot plant used in this study (Figure 1a) consists of two treatment lines (A and B) which can be operated independently or as a single treatment unit. Each line has two $0.62 \mathrm{~m}^{3}(1.25-\mathrm{m} \times 2-\mathrm{m} \times 0.25-\mathrm{m})$ flat-plate PBRs made of transparent methacrylate (0.55 $\mathrm{m}^{3}$ working volume). All four PBRs are south-facing to take full advantage of solar irradiance. Each line is connected to one polypropylene membrane tank (MT) with a total volume of $0.5 \mathrm{~m}^{3}\left(0.3 \mathrm{~m}^{3}\right.$ working volume). Each MT includes one PUR-PSH31 industrial hollow-fibre ultrafiltration membrane unit (PURON ${ }^{\circledR}$ Koch Membrane Systems, $0.03 \mu \mathrm{m}$ pore size, $31 \mathrm{~m}^{2}$ total filtering area). Two $0.1 \mathrm{~m}^{3}$ distribution chambers (DC), two $0.25 \mathrm{~m}^{3}$ clean-in-place (CIP) tanks (one for each line) and one 0.05 $\mathrm{m}^{3}$ waste tank (WT) are also included as main elements of the plant. As Figure 1a shows, the MPBR plant is provided with a roof made of transparent methacrylate. The aim of this roof was to protect the equipment from raining events. The light irradiance attenuation factor caused by the roof was low since the photobioreactors were located under the roof limits (see Figure 1a).

The MPBR plant was fed with the nutrient-rich effluent from an AnMBR plant that treats sewage. The main characteristics of the influent sewage to the AnMBR plant are chemical oxygen demand (COD) of $445 \mathrm{mg} \mathrm{COD} \cdot \mathrm{L}^{-1}$, total suspended solids (TSS) of $186 \mathrm{mg} \cdot \mathrm{L}^{-1}$, ammonium $\left(\mathrm{NH}_{4}^{+}\right)$of $27 \mathrm{mg} \mathrm{N} \cdot \mathrm{L}^{-1}$, phosphate $\left(\mathrm{PO}_{4}^{3-}\right)$ of $2.7 \mathrm{mg} \mathrm{P} \cdot \mathrm{L}^{-1}$, 
sulphate of $99 \mathrm{mg} \mathrm{S} \cdot \mathrm{L}^{-1}$, alkalinity of $293 \mathrm{mg} \mathrm{CaCO} 3 \cdot \mathrm{L}^{-1}$ and volatile fatty acids (VFA) of $11 \mathrm{mg} \mathrm{COD} \cdot \mathrm{L}^{-1}$. Further details related to the characteristics and operation of the AnMBR can be found elsewhere (Giménez et al., 2011; Robles et al., 2015).

The influent is fed into the MPBR by centrifugal pumps (P1-A and P1-B) and it is first mixed with the microalgal culture in a distribution chamber (DC1) from which it is fed equally by gravity into four photobioreactors (PBR1-A and PBR2-A in Line A; PBR1-B and PBR2-B in Line B). The microalgal culture then falls into a second distribution chamber (DC2), from where it is pumped into two membrane tanks (MT-A and MT-B). Recirculation of the microalgae is carried out by a progressing cavity pump in Line A (P3-A) and an airlift system in Line B (AS-B). The airlift system consists of two vertical transparent PVC pipes (DN $75 \mathrm{~mm}$ ) and was designed for an airflow of 0.7 $\mathrm{m}^{3} \cdot \mathrm{h}^{-1}$, providing a culture flow of $3.4 \cdot 10^{-2} \mathrm{~m} \cdot \mathrm{s}^{-1}\left(250 \mathrm{~L} \cdot \mathrm{h}^{-1}\right)$. Permeate is obtained from the membrane tanks by two rotary lobe vacuum pumps (P2-A, P2-B). A degasification vessel (DV-A and DV-B) is installed between the membrane tanks and the vacuum pump to recover the air bubbles in the effluent. The degasification vessel consists of a widened conical pipe-section that allows air accumulating at the top of this element. The obtained permeate is stored in the clean-in-place tank (CIP-A and CIP-B in Line A and Line B, respectively). The BRT is controlled by extracting a fraction of the microalgal culture from the membrane tank into a waste tank (WT) with a centrifugal pump (P4). The photobioreactors and the membrane tanks are continuously stirred by air sparging, which provides a homogenised microalgal culture and prevents wall fouling. $\mathrm{pH}$ is kept at 7.5 by introducing $\mathrm{CO}_{2}$ (99.9\%) into the system through the air recycling pipe in order to maintain a suitable environment for microalgae growth and avoid undesirable phenomena such as free ammonia stripping and phosphate precipitation. This is carried 
out by means of an on/off control valve that opens during 5 seconds when $\mathrm{pH}$ exceeds the established set-point. Although pure $\mathrm{CO}_{2}$ was used in this research study, $\mathrm{CO}_{2}$ would be added to the system from other sources when operating at full-scale, such as using the flue gases from other processes (e.g. biogas produced by the anaerobic digestion of organic carbon). Hence, the $\mathrm{CO}_{2}$ feed to the system for $\mathrm{pH}$ control has to be considered as an input for carbon dioxide footprint calculations. One compressor (C) recycles air continuously from the headspace of the photobioreactors and membrane tanks to optimise $\mathrm{CO}_{2}$ consumption.

In this work, membrane filtration permitted decoupling BRT and HRT. Nonetheless, very low net transmembrane fluxes were applied due to the high membrane filtration area compared to the applied treatment flow rate. Therefore, the obtained results from the performance of the membrane unit were not conclusive in terms of membrane fouling.

\subsection{MPBR instrumentation, automation, and control}

Several on-line sensors and automatic equipment were installed to automate and control pilot plant operations and to obtain on-line information on the state of the process.

The on-line sensors included in the MPBR plant are the following: four $\mathrm{pH}$-temperature transmitters (one in each photobioreactor); two irradiation sensors (on the surface of the flat-panels) for measuring photosynthetically active radiation (PAR); four dissolved oxygen sensors (one in each photobioreactor) to monitor photosynthetic activity during daylight hours; five liquid flow-rate transmitters (for pumps P1-A, P1-B, P2-A, P2-B and P3-A); seven level transmitters (one for MT-A, MT-B, CIP-A, CIP-B and WT and 
two in DC2); two liquid pressure transmitters for monitoring the transmembrane pressure (one in each membrane tank); one gas pressure transmitter in the compressor outlet; and five gas flow-rate transmitters (one in the air inlet of each membrane tank, one in the air inlet of each photobioreactor, one in the airlift system and one in the $\mathrm{CO}_{2}$ inlet). All temperature measurements through the manuscript refer to liquid medium temperature. On the other hand, all PAR measurements refer to daily average PAR (not instantaneous PAR), thus taking into account both daylight and night-time hours. Moreover, the irradiation sensors were vertically-oriented on the surface of the flatpanels thus recording lower irradiation intensities than when oriented horizontally. The MPBR pilot plant includes the following actuators: six frequency converters to control the rotational speed of the compressor (C) and pumps (P1-A, P1-B, P2-A, P2-B and P3-A); four regulating valves to control the air-flow inlet through the photobioreactors, air-lift system, and membrane tanks; and nine on-off valves to control biomass wastage, $\mathrm{CO}_{2}$ dosage and the membrane operation stage (filtration, back-flush, ventilation, standby, relaxation and degasification).

The plant also includes hierarchically organised control loops in the lower layer. The lower layer controllers are classical PID and on-off controllers designed to control the key operating variables: flow-rates (influent, microalgae recirculation, wastage, permeate, and gas), transmembrane pressure in both membrane tanks and level of microalgal culture in DC2, MT-A and MT-B. 


\subsection{Microalgae inoculation}

Microalgae inoculation in the MPBR was carried out as described in Viruela et al. (2016). This process consisted in a pre-cultivation phase under lab conditions (constant light and temperature of $200 \mu \mathrm{E} \cdot \mathrm{m}^{-2} \cdot \mathrm{s}^{-1}$ and $22^{\circ} \mathrm{C}$, respectively) of microalgae isolated from the secondary settler of the full-scale Carraixet WWTP (i.e. the microorganisms were already adapted to sewage). The effluent from the above-mentioned AnMBR was used as growth medium. Under these conditions, the biomass formed a stable mixed culture of microalgae mainly composed of Scenedesmus sp. (>99\%). All the PBRs of the MPBR were then started up using the laboratory-growth microalgal culture $(10 \%$ of the total working volume) and the AnMBR effluent ( $90 \%$ of the total working volume). Once the conditioning stage was achieved (i.e. stable total suspended solids) in batch mode, the PBRs were operated under automatic semi-continuous feeding mode.

\subsection{MPBR operation}

The MPBR pilot plant was operated outdoors (i.e. under variable solar irradiance and temperature) using the nutrient-loaded effluent from the AnMBR system. Table 1 shows the main characteristics of the influent entering the MPBR. The average influent nutrient concentrations to the MPBR during the experimental period were $51.3 \pm 9.7 \mathrm{mg}$ $\mathrm{NH}_{4}-\mathrm{N} \cdot \mathrm{L}^{-1}$ and $6.8 \pm 1.6 \mathrm{mg} \mathrm{PO}_{4}-\mathrm{P} \cdot \mathrm{L}^{-1}$. Nitrite and nitrate concentrations were negligible $\left(\sim 0 \mathrm{mg} \cdot \mathrm{L}^{-1}\right)$. The nutrient load entering the MPBR was variable due to both the Carraixet WWTP intake dynamics and the performance of the AnMBR.

Allylthiourea (concentration in the photobioreactors of $10 \mathrm{mg} \cdot \mathrm{L}^{-1}$ ) was used in this study to inhibit nitrification (Krustok et al., 2016; Viruela et al., 2016). Thus, the main 
process responsible of nitrogen depletion was nitrogen uptake by microalgae. Indeed, neither nitrate nor nitrite were detected in the system during the experimental period (data not shown). Allylthiourea was added to isolate processes thus assessing the potential of microalgae cultivation to enhance sustainability within the wastewater treatment field. Subsequent studies showed that nitrification can be avoided (without adding allylthiourea) by adjusting the BRT for a given environmental conditions (i.e. light intensity and temperature).

The air flow-rate into each photobioreactor was set to $2 \mathrm{~m}^{3} \cdot \mathrm{h}^{-1}$. This value was chosen to promote proper mixing conditions, avoid wall fouling and ensure adequate $\mathrm{CO}_{2}$ transference within the broth column, but also contribute to reduce the light limitation effect. The air sparging intensity in each membrane tank was set to $5 \mathrm{~m}^{3} \cdot \mathrm{h}^{-1}$ to provide suitable shear conditions over the membrane surface.

The experimental set-up consisted of different periods within which the MPBR was operated under different conditions as regards: BRT; nutrient loading rate (NLR); temperature; solar irradiance; algae culture recycling mode through the membrane tank; and relation between membrane tank volume (dark volume) and PBRs volume, i.e. nonphotic volume fraction (Molina et al., 2001), calculated as the ratio between the membrane tank volume (fractional culture volume that does not receive light, nonphotic volume) and the PBR volume (fractional culture volume that receives light, i.e. photic volume fraction).

Table 2 summarises the operating conditions (duration of the experiment, BRT and PBRs volume) and the daily average outdoor environmental conditions (temperature 
and solar irradiance) along the experiments. As commented before, daily average solar irradiance was also calculated for 24-h.

\subsubsection{Influence of algae culture recirculation mode, temperature and NLR}

Table 2 gives the operating and environmental conditions of the first operating period (78 days), which was divided into two sub-periods (i1 and i2) according to variations in NLR, solar irradiance, and temperature. During this period, the two lines of the MPBR were operated under similar environmental conditions and the only significant difference was the pumping system used for recycling the algae culture through the membrane tanks (progressing cavity pump in Line A and airlift system in Line B). The algal culture recycling velocity was set to $4.8 \cdot 10^{-2} \mathrm{~m} \cdot \mathrm{s}^{-1}\left(350 \mathrm{~L} \cdot \mathrm{h}^{-1}\right)$ and $3.4 \cdot 10^{-2} \mathrm{~m} \cdot \mathrm{s}^{-1}$ $\left(250 \mathrm{~L}^{-} \mathrm{h}^{-1}\right)$ in Line A and B, respectively. Both lines worked with an algae culture working volume of $1.1 \mathrm{~m}^{3}$ and 8 days of BRT.

\subsubsection{Influence of BRT}

Table 2 shows the main operating and environmental conditions of the second operating period (41 days), which was divided into two sub-periods (ii1 and ii2), mainly according to the modifications in the BRT. During this period, the two treatment lines were operated as a single treatment unit, i.e. the four photobioreactors were connected to one membrane tank (algae culture working volume of $2.2 \mathrm{~m}^{3}$ in the photobioreactors and $0.3 \mathrm{~m}^{3}$ in the membrane tank). The pumping system used for recycling the algae culture through the membrane tank was the progressing cavity pump $\left(4.8 \cdot 10^{-2} \mathrm{~m} \cdot \mathrm{s}^{-1}\right)$.

\subsubsection{Influence of non-photic volume fraction and feed-waste strategy}

A third experiment was carried out divided into two sub-periods (iii1 and iii2) to study the influence of the non-photic volume fraction on biomass productivity and NRR. 
Specifically, the non-photic volume percentage was reduced from sub-period iii1 to iii2 by doubling the photobioreactor working volume (from 1.1 to $2.2 \mathrm{~m}^{3}$, respectively). Hence, the non-photic volume fraction was reduced from $27.2 \%$ in sub-period iii 1 to 13.6\% in sub-period iii2. In both sub-periods, BRT was set to 9 days, NLR remained nearly stable and the recirculation of algae culture was carried out by mechanical pumping $\left(4.80 \cdot 10^{-2} \mathrm{~m} \cdot \mathrm{s}^{-1}\right)$. Table 2 gives the main operating and environmental conditions of the third operating period.

\subsection{MPBR performance monitoring}

Nitrogen-NRR (mg N $\left.\cdot \mathrm{L}^{-1} \cdot \mathrm{d}^{-1}\right)$, phosphorus-NRR $\left(\mathrm{mg} \mathrm{P} \cdot \mathrm{L}^{-1} \cdot \mathrm{d}^{-1}\right)$ and biomass productivity (mg VSS $\cdot \mathrm{L}^{-1} \cdot \mathrm{d}^{-1}$ and $\mathrm{g}$ VSS $\cdot \mathrm{m}^{-2} \cdot \mathrm{d}^{-1}$ ) were calculated as follows:

Nitrogen $-\mathrm{NRR}=\frac{Q \cdot\left(N_{i}-N_{e}\right)}{\mathrm{V}_{P B R}}$

Phosphorus $-\mathrm{NRR}=\frac{Q \cdot\left(P_{i}-P_{e}\right)}{\mathrm{V}_{P B R}}$

Biomass productivity $($ per volume of $\mathrm{PBR})=\frac{Q_{W} \cdot \mathrm{X}_{\mathrm{VSS}}}{\mathrm{V}_{P B R}}$

Biomass productivity (per surface of $\mathrm{PBR})=\frac{Q_{W} \cdot \mathrm{X}_{\mathrm{VSS}}}{\mathrm{S}_{P B R}}$

where $Q$ is the treatment flow rate $\left(\mathrm{m}^{3} \cdot \mathrm{d}^{-1}\right), \mathrm{N}_{\mathrm{i}}$ is the concentration of nitrogen in the

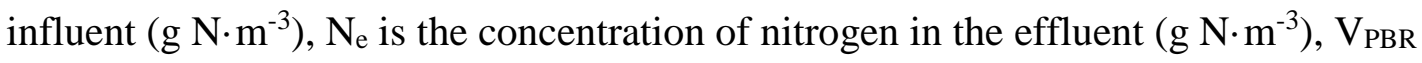
$\left(\mathrm{m}^{3}\right)$ is the total volume of the PBRs, $\mathrm{P}_{\mathrm{i}}$ is the concentration of phosphorus in the influent $\left(\mathrm{g} \mathrm{P} \cdot \mathrm{m}^{-3}\right), \mathrm{P}_{\mathrm{e}}$ is the concentration of phosphorus in the effluent $\left(\mathrm{g} \mathrm{P} \cdot \mathrm{m}^{-3}\right), \mathrm{Q}_{\mathrm{w}}$ $\left(\mathrm{m}^{3} \cdot \mathrm{d}^{-1}\right)$ is the flow rate of wasted biomass, $\mathrm{S}_{\mathrm{PBR}}\left(\mathrm{m}^{2}\right)$ is the total surface of PBRs 
exposed to solar irradiance, and $\mathrm{XVSS}_{\mathrm{VSS}}\left(\mathrm{g} \mathrm{VSS} \cdot \mathrm{m}^{-3}\right.$ ) is the volatile suspended solids concentration in the PBRs.

The theoretical maximum energy recovery from the valorisation through anaerobic digestion of the generated algal biomass $\left(\mathrm{kWh} \cdot \mathrm{m}^{-3}\right)$ and the theoretical $\mathrm{CO}_{2}$ biofixation $\left(\mathrm{kg} \mathrm{CO} \cdot \mathrm{m}^{-3}\right)$ resulting from the growth of the algal biomass were calculated using Equation 5 and Equation 6, respectively. The chemical formula reported by Green et al. (1996) for stoichiometric calculations of algal biomass was used in this study $\left(\mathrm{C}_{106} \mathrm{H}_{181} \mathrm{O}_{45} \mathrm{~N}_{16} \mathrm{P}\right)$.

Energy recovery $=\frac{\mathrm{BM}_{1} \cdot \mathrm{Y}_{\mathrm{CH} 4} \cdot \mathrm{LHV} \cdot \eta}{\mathrm{Q}} \quad$ (Eq. 5)

$\mathrm{CO}_{2}$ biofixation $=\frac{\mathrm{BM}_{2}}{\mathrm{Y}_{\mathrm{CO} 2} \cdot \mathrm{Q}} \quad$ (Eq. 6)

where $\mathrm{BM}_{1}$ is the algal biomass production rate in terms of $\mathrm{kg} \mathrm{COD} \cdot \mathrm{d}^{-1}, \mathrm{Y}_{\mathrm{CH} 4}$ is the theoretical methane yield $\left(0.35 \frac{\mathrm{m}^{3} \mathrm{CH} 4}{\mathrm{~kg} \mathrm{COD}}\right)$, $\mathrm{LHV}$ is the lower heating value for methane $\left(\mathrm{kWh} \cdot \mathrm{m}^{-3}\right), \eta$ is the power generation efficiency of a microturbine for electrical production from methane (set to $30 \%$ in this study), $\mathrm{BM}_{2}$ is the algal biomass production rate in terms of $\mathrm{kg} \mathrm{VSS} \cdot \mathrm{d}^{-1}$, and $\mathrm{Y}_{\mathrm{CO} 2}$ is the stoichiometric $\mathrm{CO}_{2}$ capture for microalgae growth $\left(0.52 \frac{\mathrm{kg} \mathrm{VSS}}{\mathrm{kg} \mathrm{CO}_{2}}\right)$.

The photosynthetic efficiency (PE) was calculated using Equation 7 (Soletto et al., 2018):

$\operatorname{PE}(\%)=\frac{\mathrm{r}_{\mathrm{G}} \cdot \mathrm{H}_{\mathrm{G}}}{\mathrm{IPAR}} \cdot 100$ 
where $\mathrm{r}_{\mathrm{G}}$ is the daily biomass growth $\mathrm{g}$ VSS $\cdot \mathrm{d}^{-1}, \mathrm{H}_{\mathrm{G}}$ is the enthalpy of dry biomass (22.9 $\mathrm{kJ} \mathrm{g}^{-1} \mathrm{VSS}$ ), and IPAR was calculated by multiplying PAR by the illuminated surface area $\left(\mathrm{m}^{2}\right)$ and a conversion factor $18.78 \mathrm{~kJ} \cdot \mathrm{s} \cdot \mathrm{d}^{-1}$.

\subsection{Sample and analytical methods}

Grab samples were collected from influent, algae culture and effluent three times per week in order to evaluate the MPBR performance in terms of nutrient recovery and biomass productivity. Ammonium $\left(\mathrm{NH}_{4}^{+}\right)$, nitrite $\left(\mathrm{NO}_{2}^{-}\right)$, nitrate $\left(\mathrm{NO}_{3}^{-}\right)$and phosphate $\left(\mathrm{PO}_{4}^{3-}\right)$ were determined according to Standard Methods (APHA, 2005) (4500-NH3-G, 4500-NO2-B, 4500-NO3-H, and 4500-P-F, respectively) in a Smartchem 200 automatic analyser (Westco Scientific Instruments, Westco). Total suspended solids (TSS) and volatile suspended solids (VSS) were also measured for the algae culture (APHA, 2005) (method $2540 \mathrm{E}$ ). All the analytical measurements were performed in duplicate. Morphological identification and cell quantification of microalgae were performed by epifluorescence microscopic methods using a Leica DM2500 microscope.

\subsection{Partial least squares regression (PLSR)}

PLSR algorithm (Wold et al., 2001) was assessed in order to evaluate the effect of different environmental and operating factors (i.e. predictors, $\mathrm{X}$ ) on process performance indicators (i.e. responses, Y). In this work, the set of predictors (X block) evaluated were the nitrogen to phosphorus ratio in the influent, the daily average temperature, the daily maximum temperature and the daily average solar irradiance. The responses $(\mathrm{Y})$ evaluated consisted of the biomass productivity, the NRR referred to 
nitrogen (N-NRR), and the NRR referred to phosphorus (P-NRR). The PLSR analysis was conducted using the mixOmics library (http://www.mixOmics.org) through the software R version 3.2.3 (http://www.R-project.org).

\section{Results and discussion}

As commented before, the experimental set-up consisted of different periods within which the MPBR was operated under different conditions as regards: BRT; NLR; temperature; solar irradiance; algae culture recycling mode through the membrane tank; and relation between membrane tank volume (dark volume) and PBRs volume, i.e. nonphotic volume fraction.

\subsection{Influence of algae culture recirculation mode, temperature and NLR}

Figure 2 and Figure 3 show the resulting algal biomass productivity and NRR, the daily average and maximum temperature and the solar irradiance in both lines during period i. As these figures show, biomass productivity (Figure 2) and NRR (Figure 3) were rather similar in both treatment lines. With regard to phytoplankton, Scenedesmus sp. remained as the predominant species (>99\%) in both systems. These results suggest that the algae recirculation mode (pumping/airlift system) did not affect algae diversity and process performance within the evaluated range of operating and environmental conditions. The results obtained in this study are contrary to Scarsella et al. (2012), who reported that the effective growth rate of Scenedesmus sp. is significantly reduced when culture recirculation is accomplished by a mechanical pump (specifically a centrifugal pump) rather than an air-lift system. The results in Scarsella et al. (2012) were achieved 
when operating at flow-rates of $1300 \mathrm{~L} \cdot \mathrm{h}^{-1}$ (velocity of $8.2 \cdot 10^{-2} \mathrm{~m} \cdot \mathrm{s}^{-1}$ ). Thus, the discrepancy between the results of Scarsella et al. (2012) and this study could be explained not only by the type of mechanical pump used (progressing cavity pump vs. centrifugal pump), but also by possible shear-stress caused by the velocity imposed on the microalgal culture $\left(4.0 \cdot 10^{-2} \mathrm{~m} \cdot \mathrm{s}^{-1}\right.$ in this study vs. $8.2 \cdot 10^{-2} \mathrm{~m} \cdot \mathrm{s}^{-1}$ in Scarsella et al., 2012). The results obtained in the present work revealed that the process can be adequately operated through different pumping methods, thus being possible to optimise the process in terms of energy demand and environmental impact (e.g. carbon footprint) by selecting adequate pumping systems, while keeping NRR and biomass productivity in adequate levels.

Differences in biomass productivity and NRR were observed between sub-periods i1 and i2 due to variations in NLR, temperature and solar irradiance. Important to highlight is the significant variability observed in NRR mainly due to the dynamics in solar irradiance, which strongly affected nutrient uptake by algal biomass.

As Figure 2 shows, biomass productivity remained fairly stable at the end of sub-period i1 (see days 8 to 16 ) and NRR yielded values of $5.86 \mathrm{mg} \mathrm{N} \cdot \mathrm{L}^{-1} \cdot \mathrm{d}^{-1}$ and $0.56 \mathrm{mg} \mathrm{P} \cdot \mathrm{L}^{-1} \cdot \mathrm{d}^{-}$ ${ }^{1}$. However, during sub-period i2, a significant drop in algal biomass production was observed in both lines, resulting in an average value of $12.4 \mathrm{mg} \mathrm{VSS} \cdot \mathrm{L}^{-1} \cdot \mathrm{d}^{-1}$ (areal productivity of $\left.2.97 \mathrm{~g} \mathrm{VSS} \cdot \mathrm{m}^{-2} \cdot \mathrm{d}^{-1}\right)$. With regard to nitrogen recovery rate, it also experienced a reduction in both lines, from 5.86 to $4.22 \mathrm{mg} \mathrm{N} \cdot \mathrm{L}^{-1} \cdot \mathrm{d}^{-1}$ in average in subperiod i1 and i2, respectively. This could be associated with the temperature increase recorded in period i (see Figure 3), reaching average daily values of $30.7^{\circ} \mathrm{C}$, thus affecting microalgae growth rate. Ras et al. (2013) highlighted the importance of temperature in outdoor microalgae cultivation, since high temperatures (i.e. above that 
one for optimal growth) are more deleterious than low temperatures. Nevertheless, although the temperature remained above $25^{\circ} \mathrm{C}$ (temperature considered as optimal for Scenedesmus sp. growth by some authors such as, Xin et al., 2011), a significant increase in nitrogen recovery rate was observed around day 50 . This behaviour was attributed to an increase in light-use efficiency, due to a reduction in both the lightshading effect (i.e. biomass concentration decreased) and higher average solar irradiance (values of daily average PAR over $280 \mu \mathrm{E} \cdot \mathrm{m}^{-2} \cdot \mathrm{s}^{-1}$ ). The results obtained may indicate that high temperatures are less harmful in conditions of light saturation. Therefore, these results suggest that microalgae cultivation is a promising technology for resource recovery in locations with significant solar irradiances (e.g. vertical daily average PAR around $\left.250-350 \mu \mathrm{E} \cdot \mathrm{m}^{-2} \cdot \mathrm{s}^{-1}\right)$. In addition, MPBR technology produces a source of water susceptible of reclamation, significantly valuable for those areas with high solar irradiances where water scarcity is a key issue. A solids-free and disinfected effluent was obtained thanks to the $0.03 \mu \mathrm{m}$-pore size membrane that was used in this study.

A considerable drop in NRR was observed at the end of sub-period i2 (see days 60-78 in Figure 3), which was associated with the continuous temperature increase recorded in period i (temperature reached maximum values of $38{ }^{\circ} \mathrm{C}$ at noontime). At the end of sub-period i2, biomass production and NRR resulted in values of $10.8 \mathrm{mg} \mathrm{VSS} \cdot \mathrm{L}^{-1} \cdot \mathrm{d}^{-1}$ (areal productivity of $2.58 \mathrm{~g} \mathrm{VSS} \cdot \mathrm{m}^{-2} \cdot \mathrm{d}^{-1}$ ), $4.39 \mathrm{mg} \mathrm{N} \cdot \mathrm{L}^{-1} \cdot \mathrm{d}^{-1}$ and $0.40 \mathrm{mg} \cdot \mathrm{L}^{-1} \cdot \mathrm{d}^{-1}$. Low values of biomass productivity are associated to thermal inhibition within the microalgal culture caused by high operating temperatures. This phenomenon was also reported by Tran et al. (2014), who observed a marked decrease in biomass productivity when operating at temperatures above $35^{\circ} \mathrm{C}$ in an outdoor open raceway for mass 
cultivation of Scenedesmus sp. Figure 4a shows the effect of temperature on algal biomass productivity. The results given in this figure suggest that operating at average temperatures above approx. $25^{\circ} \mathrm{C}$ negatively affects biomass productivity. These results are in accordance with other studies that found that high temperatures significantly reduced microalgae growth rate (Béchet et al., 2010; Tran et al., 2014; Viruela et al., 2016). In particular, despite different authors have reported a wide range of the optimal temperature for Scenedesmus sp. (30-35 ${ }^{\circ} \mathrm{C}$ reported by Sanchez et al., 2008), Xin et al. (2011) reported that Scenedesmus sp. presents optimal growth rates at temperatures around $25{ }^{\circ} \mathrm{C}$, which supports the results obtained in this work. An economic and environmental assessment should be conducted in order to adequately determinate the feasibility of MPBR technology for resource recovery at different locations, accounting for given environmental conditions affecting biomass productivity and NRR.

Figure 4b shows the PLSR analysis results obtained from the data from period i. Specifically, this figure shows the correlation circles plots obtained from the integration of the selected predictors (Influent N:P, T, Tmax and PAR) and responses (BioProd, NNRR and P-NRR). The use of correlation circle plots through the PLSR analysis allows visualising the relationship between the selected predictors and the responses (González et al., 2012).

In Figure 4b, the correlation between a predictor (Influent N:P, T, Tmax and PAR) and a response (BioProd, N-NRR and P-NRR) can be visualised through the angle formed by the projection of the variables on the axis defined by the component. The correlation is positive whether the formed angle is sharp, while the correlation is negative if the angle is obtuse. On the other hand, if the angle is right the correlation is null. As Figure 4b shows, the variables are projected inside a circle of radius 1 onto the space spanned 
by the two first principal components PC1 and PC2. The longer the distance from the origin, the stronger the relationship between the variables (González et al., 2012). Moreover, the higher the contribution of the principal components that defines the axis where the variables are projected, the stronger the relationship between the variables. In this case, the two first principal components PC1 and PC2 represent the $69.4 \%$ and $26.2 \%$ of the total variance, respectively. Figure $4 \mathrm{~b}$ illustrates that biomass productivity was inversely correlated not only with temperature (as Figure 4a showed) but also with solar irradiance. These variables ( $\mathrm{T}$ and PAR) were projected near the circle of radius 1 , which indicates that these relationships can be directly interpreted (González et al., 2012). In this respect, the microalgal culture during period i should be affected by both the photoinhibition effect and the high deleterious temperature. Instantaneous PAR values reached maximum daily values around $1400 \mu \mathrm{E} \cdot \mathrm{m}^{-2} \cdot \mathrm{s}^{-1}$ (see Figure S1 in Supplementary Material).

In the case of phosphorus recovery rate (P-NRR), is affected by the nitrogen to phosphorus influent ratio, but in a lower degree than biomass productivity by temperature and light intensity (PC2 represents the 26.2\% of total variance and these variables are inside the circle of radius 0.5). Specifically, P-NRR resulted inversely affected by the nitrogen to phosphorus influent ratio, meaning that higher phosphorus concentration in the influent enhances phosphorus recovery by microalgae accumulation. Similar results were obtained by Marcilhac et al. (2015) during microalgae-bacterial cultivation with digestate supernatant as growing media. Further experimental data under different operational conditions (e.g. long-term operation or operating at different $\mathrm{N}: \mathrm{P}$ influent ratio) should be necessary to obtain more rigorous statistical correlations. 
Concerning energy recovery, period i resulted in biomass productivities from 15 to 38 mg COD $\cdot \mathrm{L}^{-1} \cdot \mathrm{d}^{-1}$, corresponding with theoretical maximum methane productions from 0.005 to $0.013 \mathrm{LCH}_{4} \mathrm{STP}^{\cdot} \mathrm{L}^{-1} \cdot \mathrm{d}^{-1}$ if accounting for a theoretical methane yield of $350 \mathrm{~mL}$ $\mathrm{CH}_{4}$ (STP) per g of COD removed. The biomethane potential will be lower than the theoretical one depending on the operational conditions, the type of pre-treatment applied and the biomass composition, among others.

Assuming a power generation efficiency of 30\% for a combined heat and power system, the theoretical maximum electricity production for a biomethane potential of $100 \%$ could be as high as $0.20 \mathrm{kWh}$ per $\mathrm{m}^{3}$ of treated water, which enhances the energy balance of WRRFs based on this green technology. The energy demand of current activated sludge systems is estimated in $0.67 \mathrm{kWh}$ per $\mathrm{m}^{3}$ of treated water according to the Spanish Institute for Energy Diversification and Saving.

Regarding carbon footprint, this maximum electricity production from algal biomass can save up to $0.06 \mathrm{~kg} \mathrm{CO}_{2}$ per $\mathrm{m}^{3}$ of treated water, accounting for an energy mix with a carbon footprint of around $0.3 \mathrm{~kg} \mathrm{CO} 2$ eq. per $\mathrm{kWh}$ (e.g. Spain). In addition, carbon dioxide biofixation for algal biomass generation accounted for up to $0.23 \mathrm{~kg} \mathrm{CO}_{2}$ per $\mathrm{m}^{3}$ of treated water when assuming the typical composition of algal biomass reported by Green et al. (1996) $\left(\mathrm{C}_{106} \mathrm{H}_{181} \mathrm{O}_{45} \mathrm{~N}_{16} \mathrm{P}\right)$, which enhances the environmental feasibility of microalgae cultivation technologies. Hence, a theoretical carbon input of around $0.29 \mathrm{~kg}$ $\mathrm{CO}_{2}$ per $\mathrm{m}^{3}$ of treated water could be achieved under the operating conditions of period i.

Biomass productivity at the pseudo-steady state of sub-period i1 and sub-period i2 was around 22 and $11 \mathrm{mg} \mathrm{VSS} \cdot \mathrm{L}^{-1} \cdot \mathrm{d}^{-1}$, respectively. These values result in a PE of approx. 
2.7 and $1.4 \%$, respectively. These values are below the typical values obtained in flatpanel PBRs (Norsker et al., 2011), which indicates that further optimisation of the process is possible.

\subsection{Influence of BRT}

Figure 5 gives the resulting algal biomass productivity (Figure 5a), NRR (Figure 5b) and daily average temperature, and solar irradiance during period ii. Sub-period ii1, which was operated at 4.5 days of BRT and average temperature and PAR values of $28.7^{\circ} \mathrm{C}$ and $378 \mu \mathrm{E} \cdot \mathrm{m}^{-2} \cdot \mathrm{s}^{-1}$, respectively, resulted in an average biomass productivity of $51.2 \mathrm{mg} \mathrm{VSS} \cdot \mathrm{L}^{-1} \cdot \mathrm{d}^{-1}$ (areal productivity of $12.24 \mathrm{~g} \mathrm{VSS} \cdot \mathrm{m}^{-2} \cdot \mathrm{d}^{-1}$ ). After increasing BRT to 9 days in sub-period ii2, there was a significant reduction in algal biomass productivity, obtaining a mean value of $32.2 \mathrm{mg} \mathrm{VSS} \cdot \mathrm{L}^{-1} \cdot \mathrm{d}^{-1}$ (areal productivity of $7.7 \mathrm{~g}$ VSS $\left.\cdot \mathrm{m}^{-2} \cdot \mathrm{d}^{-1}\right)$. During sub-period ii2 the daily average temperature fell considerably (from 30 to $22^{\circ} \mathrm{C}$ ), as well as the daily average solar irradiance, which was characterised by strong dynamics with frequent low values. Biomass productivity during sub-period ii2 remained fairly constant, despite the continuous reduction in solar irradiance and temperature, suggesting that, in comparison with BRT, temperature and light variations had no significant influence on biomass productivity within the evaluated range of operating conditions. The differences in biomass productivity between sub-periods ii1 and ii2 were mainly attributed to the increase in BRT. This fact highlights the potential of BRT as control parameter in order to maximise resource recovery in MPBR systems. Indeed, BRT is a key parameter for palliating the effect of environmental conditions (i.e. variations on light intensity and temperature) on process performance and allows working at low HRTs (Luo et al., 2016). 
Since BRT was doubled by halving the wasted volume of microalgae, the biomass concentration should have risen considerably to keep productivity constant. However, a rise in biomass concentration of only $23 \%$ was observed during operating period ii (from $370 \mathrm{mg}$ VSS $\cdot \mathrm{L}^{-1}$ in sub-period ii1 to $471 \mathrm{mg} \mathrm{VSS} \cdot \mathrm{L}^{-1}$ in sub-period ii2), which indicated reduced biomass productivity. This increase in biomass concentration could have favoured the light shading effect that negatively influences the cell growth rate (see, for instance, Cuaresma et al., 2011), and could explain the reduced biomass productivity in sub-period ii2.

In contrast to the reduced biomass productivity at the beginning of sub-period ii2, NRR remained at high values $\left(8.12 \mathrm{mg} \mathrm{N} \cdot \mathrm{L}^{-1} \cdot \mathrm{d}^{-1}\right.$ and $\left.0.95 \mathrm{mg} \mathrm{P} \cdot \mathrm{L}^{-1} \cdot \mathrm{d}^{-1}\right)$ until day $23 . \mathrm{In}$ addition, the specific nutrient uptake rates (with respect to VSS) also remained high: $30.1 \mathrm{mg} \mathrm{N} \cdot \mathrm{gVSS}^{-1} \cdot \mathrm{d}^{-1}$ and $4.0 \mathrm{mg} \mathrm{P} \cdot \mathrm{gVSS}^{-1} \cdot \mathrm{d}^{-1}$. However, NRR was reduced as temperature and solar irradiance declined throughout sub-period ii2. At the end of subperiod ii2, nitrogen and phosphorus recovery yielded values of $3.3 \mathrm{mg} \mathrm{N} \cdot \mathrm{L}^{-1} \cdot \mathrm{d}^{-1}$ and $0.38 \mathrm{mg} \mathrm{P} \cdot \mathrm{L}^{-1} \cdot \mathrm{d}^{-1}$. These results revealed that the combined effects of reducing daily average temperature and PAR from 28.7 to $23.9^{\circ} \mathrm{C}$ and from 378 to $343 \mu \mathrm{E} \cdot \mathrm{m}^{-2} \cdot \mathrm{s}^{-1}$ on average, respectively, and increasing BRT from 4.5 to 9 days resulted in a reduction of about 30\% in NRR. Another important effect observed in this period was that solar irradiance seemed to have a short-term effect on nutrient uptake (nitrogen and phosphorus), whilst the results obtained suggest that the same environmental factor has a more delayed effect on biomass productivity. Hence, as commented before, BRT should be modified accounting for variations on temperature and PAR in order to optimise resource recovery in MPBRs. 
The NRR obtained in this study was higher than the daily NRR reported by Ji et al. (2014) in batch experiments using a novel green algae strain identified as Desmodesmus sp., which was fed with anaerobic digestion effluent under light/dark cycles. Park et al. (2010) also reported similar recovery rates (around 5-6 $\mathrm{mg} \mathrm{N} \cdot \mathrm{L}^{-1} \cdot \mathrm{d}^{-1}$ ) to Ji et al. (2014), by Scenedesmus sp. from the effluent of an anaerobic digester obtained from a piggery farm. However, the NRR results obtained in this study are significantly lower than the maximum NRR $\left(19.53 \mathrm{mg} \mathrm{N} \cdot \mathrm{L}^{-1} \cdot \mathrm{d}^{-1}\right.$ and $\left.3.7 \mathrm{mg} \mathrm{P} \cdot \mathrm{L}^{-1} \cdot \mathrm{d}^{-1}\right)$ reported by Ruiz-Martinez et al. (2012) at bench-scale under 24-h optimal light and temperature conditions and treating the same AnMBR effluent as the one used in the present study. Marcilhac et al. (2015) also obtained higher NRR $\left(10.1 \mathrm{mg} \mathrm{N} \cdot \mathrm{L}^{-1} \cdot \mathrm{d}^{-1}\right.$ and $\left.2.0 \mathrm{mg} \mathrm{P} \cdot \mathrm{L}^{-1} \cdot \mathrm{d}^{-1}\right)$ for Scenedesmus sp. in batch experiments at bench-scale with artificial illumination (in $12 \mathrm{~h}$ dark/12 h light cycle) while treating digestate supernatant. The present study was conducted outdoors (i.e. temperature and light intensity was not controlled), aiming to represent the expected conditions of systems of this type at full-scale. Indeed, Van Den Hende et al. (2014) also reported a decrease in NRR when up-scaling microalgae cultivation from lab reactors to an outdoor pilot-scale raceway pond.

With regard to areal biomass productivity, the maximum value obtained in this study $\left(15.78 \mathrm{~g} \mathrm{VSS} \cdot \mathrm{m}^{-2} \cdot \mathrm{d}^{-1}\right)$ is higher than other values reported for outdoor raceway ponds (Arbib et al., 2013; Van Den Hende et al., 2014). In comparison with other MPBR systems, Xu et al. (2014) reported lower average biomass productivities (32.5 mg VSS $\cdot \mathrm{L}^{-1} \cdot \mathrm{d}^{-1}$ and $6.2 \mathrm{~g} \mathrm{VSS} \cdot \mathrm{m}^{-2} \cdot \mathrm{d}^{-1}$ ) than the ones reported in this study. Xu et al. (2014) worked with flat-panel PBR coupled with a submerged membrane module at benchscale for P recovery in synthetic wastewater using Chlorella sp. However, the operating conditions are not fully comparable, since artificial lighting (in 12 h dark/12 h light 
cycle) was used by Xu et al. (2014), and an SRT and HRT of 180 and 1 days were set, respectively.

Figure 6 shows sample plot resulting from the principal component analysis of the 11 data sets from period ii, considering the explicative variables (Influent N:P, T and PAR) and responses (BioProd, N-NRR and P-NRR). The diagram is formed by projecting in plans the two first principal components or latent variables PC1 and PC2. The data from sub-period ii1 are located in the left-down side of the principal components diagram, in contrast to the data from sub-period ii2 which are more distributed mainly in the right side. These results corroborate the differences observed while operating at different BRT, i.e. a significant decrease in NRR and biomass productivity was reached when shifting BRT from 4.5 to 9 days.

Analysing the overall process, the performance of this outdoor pilot-scale MPBR illustrates that further process optimisation is required to achieve higher microalgae productivity and nutrient recovery efficiency. Enhanced results regarding energy recovery and carbon footprint reduction were reached during period ii mainly due to the higher solar intensity recorded within this period in comparison with period i (see Table 2). In this respect, more solar energy was harvested, thus increasing the economic and environmental feasibility of the technology. Within period ii, theoretical maximum methane productivities from 0.015 to $0.033 \mathrm{LCH}_{\mathrm{STP}} \cdot \mathrm{L}^{-1} \cdot \mathrm{d}^{-1}$ would be achieved, corresponding to theoretical maximum electricity production of up to $0.43 \mathrm{kWh}$ per $\mathrm{m}^{3}$ of treated water. Concerning carbon footprint, maximum savings of up to $0.13 \mathrm{~kg} \mathrm{CO} 2$ per $\mathrm{m}^{3}$ of treated water could be achieved from energy recovery. Carbon dioxide biofixation for algal biomass growth would account for up to $0.51 \mathrm{~kg} \mathrm{CO}_{2}$ per $\mathrm{m}^{3}$ of 
treated water. Hence, a theoretical carbon input of around $0.64 \mathrm{~kg} \mathrm{CO}_{2}$ per $\mathrm{m}^{3}$ of treated water could be achieved under similar operating conditions to the ones from period ii.

Biomass productivity at the pseudo-steady state of sub-period ii1 and sub-period ii2 was around 51 and $32 \mathrm{mg} \mathrm{VSS} \cdot \mathrm{L}^{-1} \cdot \mathrm{d}^{-1}$, respectively. These values result in a PE of approx. 6.3 and $4.0 \%$, respectively. Therefore, enhanced performance was achieved during this period compared to period i. Indeed, sub-period ii1 resulted in PE values above the typical PE value of 5\% observed in flat-panel PBRs (Norsker et al., 2011). Nevertheless, these values are still below than the maximum theoretical PE value of 9\% (see e.g. Jonker and Faaij, 2013).

\subsection{Influence of the non-photic volume fraction}

The results obtained in operating period iii (see Table 3) revealed that the non-photic volume fraction is a key factor to be minimised in order to optimise the feasibility of MPBR for sewage treatment. Reducing the non-photic volume fraction from $27.2 \%$ (sub-period iii1) to $13.6 \%$ (sub-period iii2) resulted in an increase of $40 \%$ in biomass productivity. Specifically, biomass productivity increased from 21.9 in sub-period iii1 to $30.6 \mathrm{mg} \mathrm{VSS} \cdot \mathrm{L}^{-1} \cdot \mathrm{d}^{-1}$ in sub-period iii2, which corresponds to an increase in the areal productivity from 5.24 to $7.32 \mathrm{~g} \mathrm{VSS} \cdot \mathrm{m}^{-2} \cdot \mathrm{d}^{-1}$, respectively. Nutrient recovery efficiency was slightly lower in sub-period iii1 $\left(6.61 \mathrm{mg} \mathrm{N} \cdot \mathrm{L}^{-1} \cdot \mathrm{d}^{-1}\right.$ and $\left.0.81 \mathrm{mg} \mathrm{P} \cdot \mathrm{L}^{-1} \cdot \mathrm{d}^{-1}\right)$ than in sub-period iii2 $\left(7.61 \mathrm{mg} \mathrm{N} \cdot \mathrm{L}^{-1} \cdot \mathrm{d}^{-1}\right.$ and $\left.0.97 \mathrm{mg} \mathrm{P} \cdot \mathrm{L}^{-1} \cdot \mathrm{d}^{-1}\right)$, which was also attributed to an increase in the amount of harvested solar energy in the latter sub-period.

The effect of the non-photic volume fraction on biomass productivity would be considerably reduced in full-scale operations, i.e. the non-photic volume fraction would 
be considerably reduced as a result of operating with reduced membrane tank volumes, thus significantly enhancing the performance of MPBRs at full-scale.

\section{Conclusions}

A MPBR plant treating the nutrient-loaded effluent from an AnMBR sewage treatment system was operated under different outdoor environmental and operating conditions. The variations recorded in temperature and solar irradiance strongly affected biomass productivity and NRR. In this study, maximum nutrient recovery rates of $7.68 \mathrm{mg} \mathrm{N} \cdot \mathrm{L}^{-}$

${ }^{1} \cdot \mathrm{d}^{-1}$ and $1.17 \mathrm{mg} \mathrm{P} \cdot \mathrm{L}^{-1} \cdot \mathrm{d}^{-1}$, and maximum biomass productivities of $66 \mathrm{mg} \mathrm{VSS} \cdot \mathrm{L}^{-1} \cdot \mathrm{d}^{-1}$ $\left(15.78 \mathrm{~g} \mathrm{VSS} \cdot \mathrm{m}^{-2} \cdot \mathrm{d}^{-1}\right)$ were achieved when operating at 4.5 days of biomass retention time. Reducing the non-photic volume fraction from $27.2 \%$ to $13.6 \%$ resulted in an increase of $40 \%$ in biomass productivity. The obtained results showed that microalgae cultivation systems could contribute to reduce the energy demand and the carbon footprint of the wastewater treatment process due to solar energy harvesting for algal biomass growth, while recovering valuable nutrients from sewage. Specifically, maximum carbon input of around $0.64 \mathrm{~kg} \mathrm{CO}_{2}$ per $\mathrm{m}^{3}$ of treated water could be achieved under favourable environmental conditions. By the use of ultrafiltration membranes (pore size of $0.03 \mu \mathrm{m}$ ), MPBR produces a high quality permeate (i.e. negligible levels of pathogens and suspended solids) which could be useful for reuse and recycling applications such as irrigation purposes. 


\section{Acknowledgements}

This research was supported by the Spanish Ministry of Economy and Competitiveness (MINECO, Projects CTM2011-28595-C02-01/02, CTM2014-54980-C2-1-R and CTM2014-54980-C2-2-R) jointly with the European Regional Development Fund (ERDF) and Generalitat Valenciana (GVA-ACOMP2013/203), which are gratefully acknowledged. The authors also like to acknowledge the support received from Generalitat Valenciana via one VALi+d post-doctoral grant (APOSTD/2014/049). 


\section{Supplementary Material}

Figure S1: Time evolution of maximum instantaneous and daily average solar irradiance

(PAR) during period i. The vertical line separates sub-period i1 and sub-period i2.

Figure S2: Time evolution of maximum instantaneous and daily average solar irradiance (PAR) during period ii. The vertical line separates sub-period ii1 and sub-period ii2. 


\section{References}

APHA, 2005. Standard methods for the examination of water and wastewater, 20th ed., American Public Health Association, Washington, DC.

Arbib, Z., Ruiz, J., Álvarez-Díaz, P., Garrido-Pérez, C., Barragan, J. ,Perales, J.A., 2013. Long term outdoor operation of a tubular airlift pilot photobioreactor and a high rate algal pond as tertiary treatment of urban wastewater. Ecol. Eng. 52, 143-153.

Ashley, K., Cordell, D. Mavinic, D., 2011. A brief history of phosphorus: From the philosopher's stone to nutrient recovery and reuse. Chemosphere 84, 737-746.

Béchet, Q., Shilton, A., Fringer, O., Munoz, R., Guieysse, B., 2010. Mechanistic modelling of broth temperature in outdoor photobioreactors. Environ. Sci. Technol. 44, 2197-2203.

Bilad, M.R., Arafat, H.A., Vankelecom I.F., 2014. Membrane technology in microalgae cultivation and harvesting: A review. Biotechnol. Adv. 32, 1283-1300.

Cuaresma, M., Janssen, M., Vílchez, C., Wijffels R.H., 2009. Productivity of Chlorella sorokiniana in a short light-path (SLP) panel photobioreactor under high irradiance. Biotechnol. Bioeng. 104, 352-359.

Do Nascimento, M., Sanchez Rizza, L., Arruebarrena Di Palma, A., Dublan, M.A., Salerno, G., Rubio, L.M., Curatti, L., 2015. Cyanobacterial biological nitrogen fixation as a sustainable nitrogen fertilizer for the production of microalgal oil. Algal Res. 12, 142-148.

Flores-Alsina, X., Corominas, LL., Snip, L., Vanrolleghem, P.A., 2011. Including greenhouse gas emissions during benchmarking of wastewater treatment plant control strategies. Water. Res. 45, 47004710.

Gao, F., Yang, Z.H., Li, C., Wang, Y.J., Jin, W.H., Deng, Y.B., 2014. Concentrated microalgae cultivation in treated sewage by membrane photobioreactor operated in batch flow mode. Bioresour. Technol. 167, 441-446.

Gao, F., Yang, Z.H., Li, C., Zeng, G.M., Ma, D.H., Zhou, L., 2015. A novel algal biofilm membrane photobioreactor for attached microalgae growth and nutrients removal from secondary effluent. Bioresour. Technol. 179, 8-12.

Ghisellini, P., Cialani, C. Ulgiati, S., 2016. A review on circular economy: the expected transition to a balanced interplay of environmental and economic systems. J. Clean. Prod. 114, 11-32. 
Giménez, J.B., Robles, A., Carretero, L., Duran, F., Ruano, M.V., Gatti, M.N., Ribes, J., Ferrer, J., Seco, A., 2011. Experimental study of the anaerobic urban wastewater treatment in a submerged hollow-fiber membrane bioreactor at pilot scale. Bioresour. Technol. 102, 8799-8806.

Green, F.B., Bernstone, L.S., Lundquist, T.J., Oswald, W.J., 1996. Advanced integrated wastewater pond systems for nitrogen removal. Water Sci. Technol. 33, 207-217.

Intergovernmental Panel on Climate Change: IPCC Guidelines for National Greenhouse Gas Inventories, Prepared by the National Greenhouse Gas Inventories Programme, Egglestone H.S., Buendia L., Miwa K., Ngara T. and Anabe K. (eds). Published 2006 by IGES, Japan. http://www.ipcccnggip.iges.or.jp/publicc/2006gl/. Volume 5: Waste, Chapter 6: Wastewater treatment and discharge.

Jankowska, E., Sahu, A.K., Oleskowicz-Popiel, P., 2017. Biogas from microalgae: Review on microalgae's cultivation, harvesting and pretreatment for anaerobic digestion. Renew. Sust. Energ. Rev. 75, 692-709. Ji, F., Liu, Y., Hao, R., Li, G., Zhou, Y., Dong, R., 2014. Biomass production and nutrients removal by a new microalgae strain Desmodesmus sp. in anaerobic digestion wastewater. Bioresour. Technol. 161, 200207.

Jonker, J.G.G., Faaij, A.P.C., 2013. Techno-economic assessment of micro-algae as feedstock for renewable bio-energy production. Applied Energy 102, 461-475.

Krustok, I., Odlare, M., Truu, J., Nehrenheim, E., 2016. Inhibition of nitrification in municipal wastewatertreating photobioreactors: Effect on algal growth and nutrient uptake. Bioresour. Technol. 202, 238-243.

Luo, Y., Le-Clech, P., Henderson, R.K., 2017. Simultaneous microalgae cultivation and wastewater treatment in submerged membrane photobioreactors: A review. Algal Res. 24, 425-437.

Marcilhac, C., Sialve, B., Pourcher, A.-M., Ziebal, C., Bernet, N., Béline, F., 2015. Control of nitrogen behaviour by phosphate concentration during microalgal-bacterial cultivation using digestate. Bioresour. Technol. 175, 224-230.

Mata, T., Martins, A.A., Caetano, N.S., 2010. Microalgae for biodiesel production and other applications: a review. Renew. Sust. Energ. Rev. 14, 217-232.

Molina, E., Fernández, J., Acién, F.G., Chisti, Y., 2001. Tubular photobioreactor design for algal cultures. J. Biotechnol. 92, 113-131.

Nicolae, B., George-Vlad, B., 2015. Life cycle analysis in refurbishment of the buildings as intervention practices in energy saving. Energ. Buildings 86, 74-85. 
Norsker, N-H., Barbosa, M.J., Vermuë, M.H., Wijffels, R.H., 2011. Microalgal production — A close look at the economics. Biotechnol. Adv. 29, 24-27.

Park, J., Jin, H., Lim, B.-R., Park, K.-Y., Lee, K., 2010. Ammonia removal from anaerobic digestion effluent of livestock waste using green alga Scenedesmus sp. Bioresour. Technol. 101, 8649-8657.

Parravicini, V., Svardal, K., Krampe, J., 2016. Greenhouse Gas Emissions from Wastewater Treatment Plants. Energy. Procedia. 97, 246-253.

Ras, M., Steyer, J.-P., Bernard, O., 2013. Temperature effect on microalgae: a crucial factor for outdoor production. Rev. Environ. Sci. Biotechnol. 12, 153-164.

Robles, A., Durán, F., Ruano, M.V., Ribes, J., Rosado, A., Seco, A., Ferrer, J., 2015. Instrumentation, control, and automation for submerged anaerobic membrane bioreactors. Environ. Technol. 25, 1-12.

Ruiz-Martinez, A., Martin Garcia, N., Romero, I., Seco, A., Ferrer, J., 2012. Microalgae cultivation in wastewater: Nutrient removal from anaerobic membrane bioreactor effluent. Bioresour. Technol. 126, 247253.

Ruiz-Rosa, I., García-Rodríguez, F.J., Mendoza-Jiménez, J., 2016. Development and application of a cost management model for wastewater treatment and reuse processes. J. Clean. Prod. 113, 299-310.

Sánchez, J.F., Fernández-Sevilla, J.M., Acién, F.G., Cerón, M.C., Pérez-Parra, J., MolinaGrima, E., 2008. Biomass and lutein productivity of Scenedesmus almeriensis: influence of irradiance, dilution rate and temperature. Appl. Microbiol.Biotechnol. 79, 719-729

Scarsella, M., Torzillo, G., Cicci, A., Belotti, G., De Flilippis, P., Bravi, M., 2012. Mechanical stress tolerance of two microalgae. Process Biochem. 47, 1603-1611.

Soletto, D., Binaghi, L., Ferrari, L., Lodi, A., Carvalho, J.C.M., Zilli, M., Converti, A., 2008. Effects of carbon dioxide feeding rate and light intensity on the fed-batch pulse-feeding cultivation of Spirulina platensis in helical photobioreactor. Biochem. Eng. J. 39, 369-375.

Tran, K.C., Mendoza Martin, J.L., Heaven, S., Banks, C.J., Acién, F.G., Molina-Grima, E., 2014. Cultivation and anaerobic digestion of Scenedesmus spp. grown in a pilot-scale open raceway. Algal Res. 5, 95-102.

Tsolcha, O.N., Tekerlekopoulou, A.G., Akratos, C.S., Aggelis, G., Genitsaris, S., Moustaka-Gouni, M., Vayenas, D.V., 2017. Biotreatment of raisin and winery wastewaters and simultaneous biodiesel production using a Leptolyngbya-based microbial consortium. J. Clean. Prod. 148, 185-193. 
Van Den Hende, S., Beelen, V., Bore, G., Boon, N., Vervaeren, H., 2014. Up-scaling aquaculture wastewater treatment by microalgal bacterial flocs: From lab reactors to an outdoor raceway pond. Bioresour. Technol. 159, 342-354.

Viruela, A., Murgui, M., Gómez-Gil, T., Durán, F., Robles, Á, Ruano, M.V., Ferrer, J., Seco, A., 2016. Water resource recovery by means of microalgae cultivation in outdoor photobioreactors using the effluent from an anaerobic membrane bioreactor fed with pre-treated sewage, Bioresour. Technol. 218, 447-454. Winans, K., Kendall, A., Deng, H. , 2017. The history and current applications of the circular economy concept. Renew. Sust. Energ. Rev. 68, 825-833.

Wold, S., Sjöström, M., Eriksson, L., 2001. PLS-regression: a basic tool of chemometrics. Chemom. Intell. Lab. Syst. 58, 109-130.

Xin, L., Hong-Ying, H., Yu-ping, Z., 2011. Growth and lipid accumulation properties of a freshwater microalga Scenedesmus sp. under different cultivation temperature. Bioresour. Technol. 102, 3098-3102. Xu, M., Bernards, M., Hu, Z., 2014. Algae-facilitated chemical phosphorus removal during high-density Chlorella emersonii cultivation in a membrane bioreactor. Bioresour. Technol. 153, 383-387. 


\section{Figure captions}

Figure 1: (a) General view of the MPBR and relative positions of the PBRs. (b) Flow diagram of the MPBR. Nomenclature: DC: distribution chamber; PBR: photobioreactor; MT: membrane tank; DV: degasification vessel; CIP: clean-in-place; WT: waste tank; P: pump; C: compressor; AS: airlift system.

Figure 2: Time evolution of biomass productivity obtained during period i: daily average VSS productivity, temperature (average and maximum) and solar irradiance. The vertical line separates sub-period i1 and subperiod i2.

Figure 3: Time evolution of nutrient recovery obtained during period i: (a) NRR (nitrogen), temperature (average and maximum) and solar irradiance (PAR); and (b) NRR (phosphorus) temperature (average and maximum) and solar irradiance (PAR). The vertical line separates sub-period i1 and sub-period i2.

Figure 4: (a) Evolution of daily average VSS productivity versus daily average temperature during period i; and (b) PLSR results from period i: correlation circles plot from the integration of the selected predictors (Influent N:P, T, Tmax and PAR) and responses (BioProd, N-NRR and P-NRR). Nomenclature: PC: Principal Component; N:P: nitrogen to phosphorus ratio in the influent; T: daily average temperature; Tmax: daily maximum temperature; PAR: light intensity; BioProd: biomass productivity; N-NRR: nutrient recovery rate referred to nitrogen; and P-NRR: nutrient recovery rate referred to phosphorus.

Figure 5: Time evolution of biomass productivity and nutrient recovery obtained during period ii: (a) VSS productivity, temperature and solar irradiance (PAR); and (b) NRR, temperature and solar irradiance (PAR). The vertical line separates sub-period ii1 and sub-period ii2.

Figure 6: PLSR results from period ii: sample plot resulting from the principal component analysis of the 11 data sets from this period. 
Table 1. Average MPBR influent characteristics during the experimental period (COD: chemical oxygen demand; VFA: volatile fatty acids).

\begin{tabular}{cc}
\hline Parameter & Mean \pm SD \\
\hline Ammonium $\left(\mathrm{mg} \mathrm{N} \cdot \mathrm{L}^{-1}\right)$ & $51.3 \pm 9.7$ \\
Orthophosphates $\left(\mathrm{mg} \mathrm{P} \cdot \mathrm{L}^{-1}\right)$ & $6.8 \pm 1.6$ \\
Nitrites $\left(\mathrm{mg} \mathrm{N} \cdot \mathrm{L}^{-1}\right)$ & $\approx 0$ \\
Nitrates $\left(\mathrm{mg} \mathrm{N} \cdot \mathrm{L}^{-1}\right)$ & $\approx 0$ \\
Total COD $\left(\mathrm{mg} \mathrm{COD} \cdot \mathrm{L}^{-1}\right)$ & $31 \pm 5$ \\
Alkalinity $\left(\mathrm{mg} \mathrm{CaCO} \cdot \mathrm{L}^{-1}\right)$ & $763 \pm 87$ \\
VFA $\left(\mathrm{mg} \mathrm{HAc} \cdot \mathrm{L}^{-1}\right)$ & $1.5 \pm 0.6$ \\
\hline
\end{tabular}


Table 2. Average operating and environmental conditions during the experimental period.

\begin{tabular}{|c|c|c|c|c|c|c|}
\hline \multirow[t]{2}{*}{ Period } & $\begin{array}{c}\text { Durati } \\
\text { on }\end{array}$ & $\begin{array}{l}\text { BRT / PBRs } \\
\text { Volume }\end{array}$ & $\begin{array}{c}\mathbf{N} \\
\text { loading } \\
\text { rate }\end{array}$ & $\begin{array}{c}\text { P loading } \\
\text { rate }\end{array}$ & $\begin{array}{c}\text { Solar } \\
\text { irradiance } \\
\text { PAR }\end{array}$ & $\begin{array}{c}\text { Temperatu } \\
\text { re }\end{array}$ \\
\hline & (d) & $(d / L)$ & $\left.\begin{array}{c}\left(\mathrm{g} \mathrm{N}^{\mathrm{N}} \cdot \mathrm{d}^{-}\right. \\
1\end{array}\right)$ & $\left(g P \cdot d^{-1}\right)$ & $\left(\mu \mathrm{E} \cdot \mathrm{m}^{-2} \cdot \mathrm{s}^{-1}\right)$ & $\left({ }^{\circ} \mathrm{C}\right)$ \\
\hline P. i1 & 15 & 8 / 1100 & $\begin{array}{c}13.9 \pm \\
3.0\end{array}$ & $1.9 \pm 0.4$ & $169 \pm 33$ & $25.8 \pm 1.4$ \\
\hline P. i2 & 63 & 8 / 1100 & $\begin{array}{c}17.9 \pm \\
3.2\end{array}$ & $2.4 \pm 0.4$ & $263 \pm 33$ & $28.7 \pm 1.5$ \\
\hline P. ii1 & 16 & 4.5 / 2200 & $\begin{array}{l}31.5 \pm \\
2.7\end{array}$ & $4.1 \pm 0.5$ & $378 \pm 78$ & $28.7 \pm 2.1$ \\
\hline P. ii 2 & 25 & 9 / 2200 & $\begin{array}{c}25.9 \pm \\
3.0\end{array}$ & $3.2 \pm 0.3$ & $343 \pm 113$ & $23.9 \pm 3.8$ \\
\hline P. iii1 & 16 & 9 / 1100 & $\begin{array}{c}13.7 \pm \\
2.5\end{array}$ & $1.9 \pm 0.3$ & $201 \pm 12$ & $25.6 \pm 1.7$ \\
\hline P. iii 2 & 10 & 9 / 2200 & $\begin{array}{c}13.1 \pm \\
3.1\end{array}$ & $1.5 \pm 0.5$ & $362 \pm 78$ & $27.5 \pm 1.5$ \\
\hline
\end{tabular}


Table 3. Average values obtained of non-photic volume fraction, biomass productivity and NRR during experimental period iii.

\begin{tabular}{|c|c|c|c|c|}
\hline \multirow[t]{2}{*}{ Period } & $\begin{array}{l}\text { Non-photic } \\
\text { volume } \\
\text { fraction }\end{array}$ & Biomass productivity & N-NRR & P-NRR \\
\hline & (\%) & $\begin{array}{c}\left(\mathrm{mg} \mathrm{VSS} \cdot \mathbf{L}^{-1} \cdot \mathbf{d}^{-1} / \mathrm{g} \mathrm{VSS} \mathrm{m}^{-}\right. \\
\left.{ }^{2} \cdot \mathrm{d}^{-1}\right)\end{array}$ & $\begin{array}{c}\left(\mathrm{mg} \mathrm{N}_{1} \cdot \mathrm{L}^{-1} \cdot \mathrm{d}^{-}\right. \\
{ }^{-}\end{array}$ & $\left(\mathbf{m g} \mathbf{P} \cdot \mathbf{L}^{-1} \cdot \mathbf{d}^{-1}\right)$ \\
\hline P. iii1 & 27.2 & $21.9 \pm 2.2 / 5.24 \pm 0.52$ & $6.61 \pm 0.56$ & $0.56 \pm 0.26$ \\
\hline P. iii2 & 13.6 & $30.6 \pm 6.54 / 7.32 \pm 1.56$ & $7.61 \pm 0.72$ & $0.97 \pm 0.03$ \\
\hline
\end{tabular}


a)
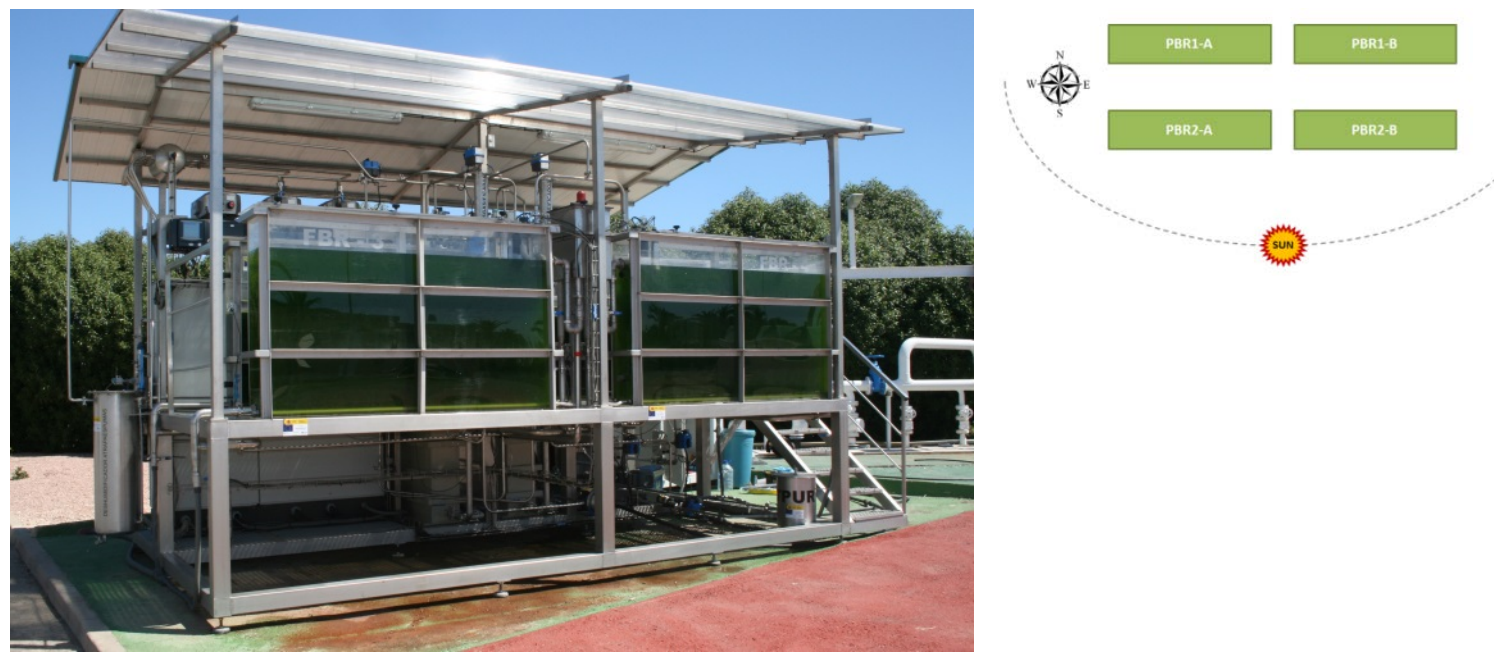

b)

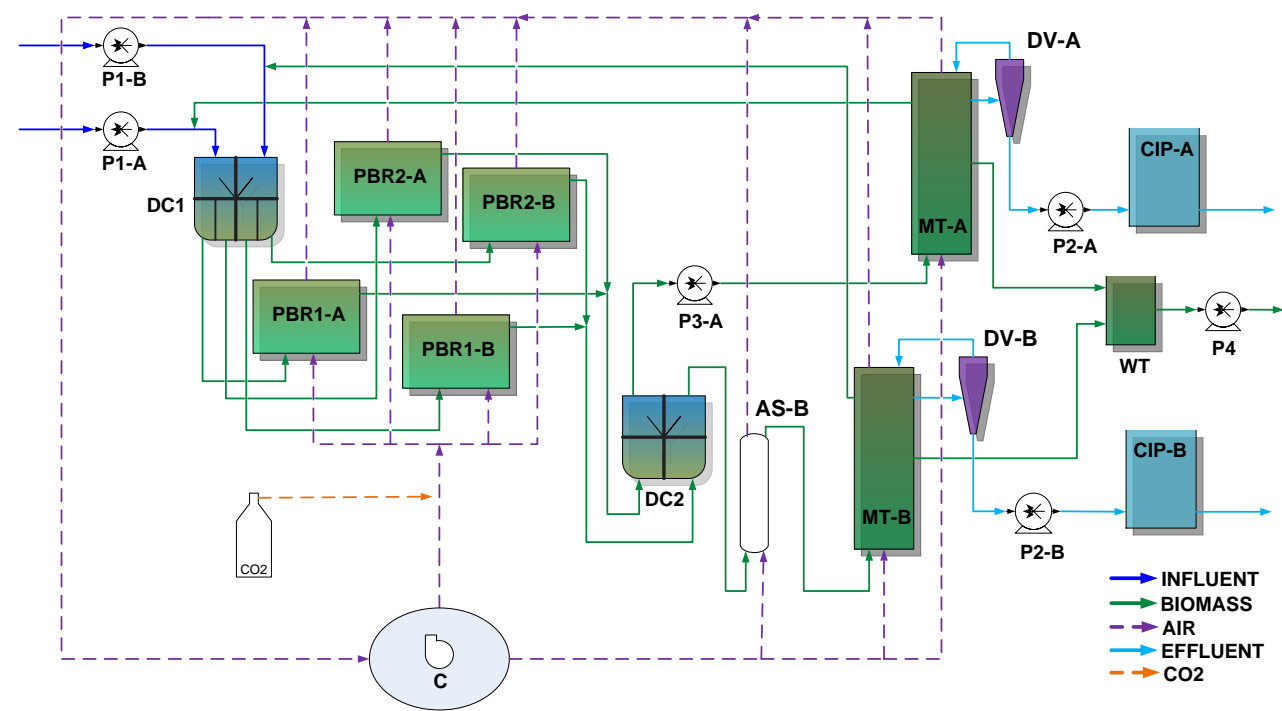

Figure 1: (a) General view of the MPBR and relative positions of the PBRs. (b) Flow diagram of the MPBR. Nomenclature: DC: distribution chamber; PBR: photobioreactor; MT: membrane tank; DV: degasification vessel; CIP: clean-in-place; WT: waste tank; P: pump; C: compressor; AS: airlift system. 


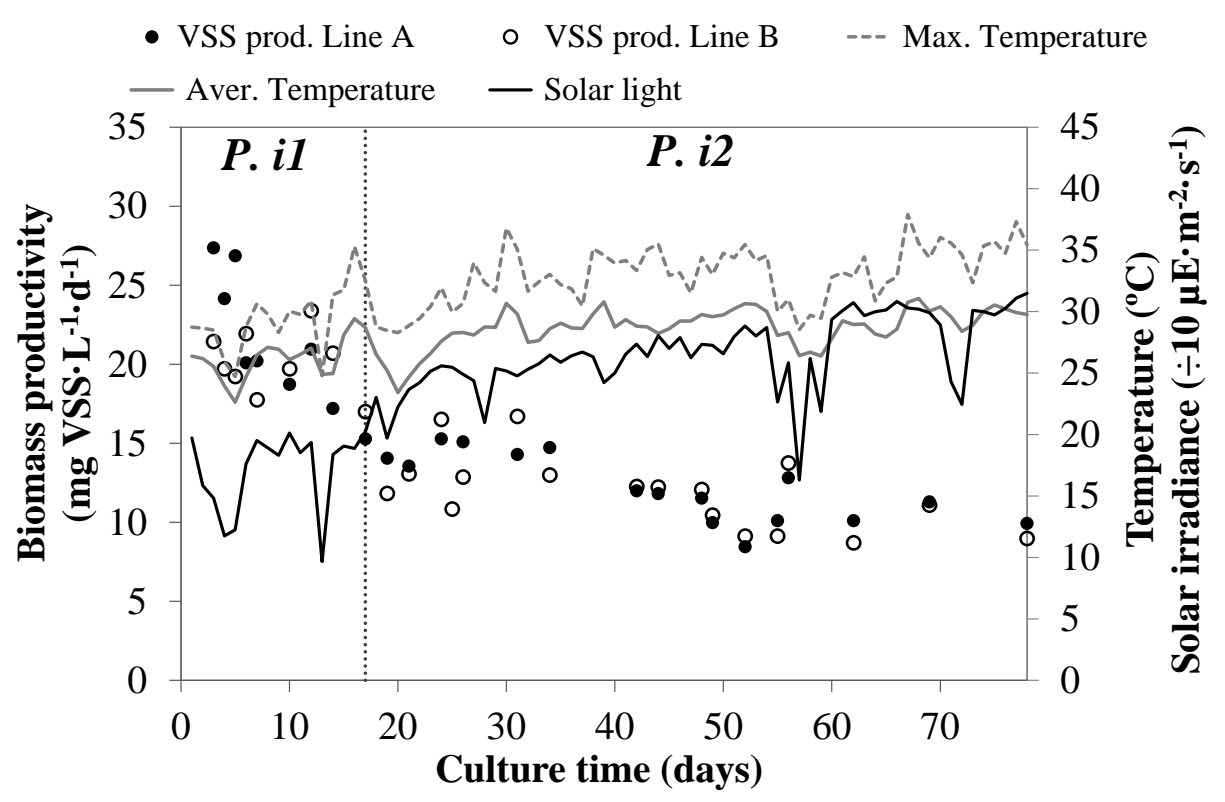

Figure 2. Time evolution of biomass productivity obtained during period i: daily average VSS productivity, temperature (average and maximum) and solar irradiance. The vertical line separates sub-period i1 and subperiod i2. 

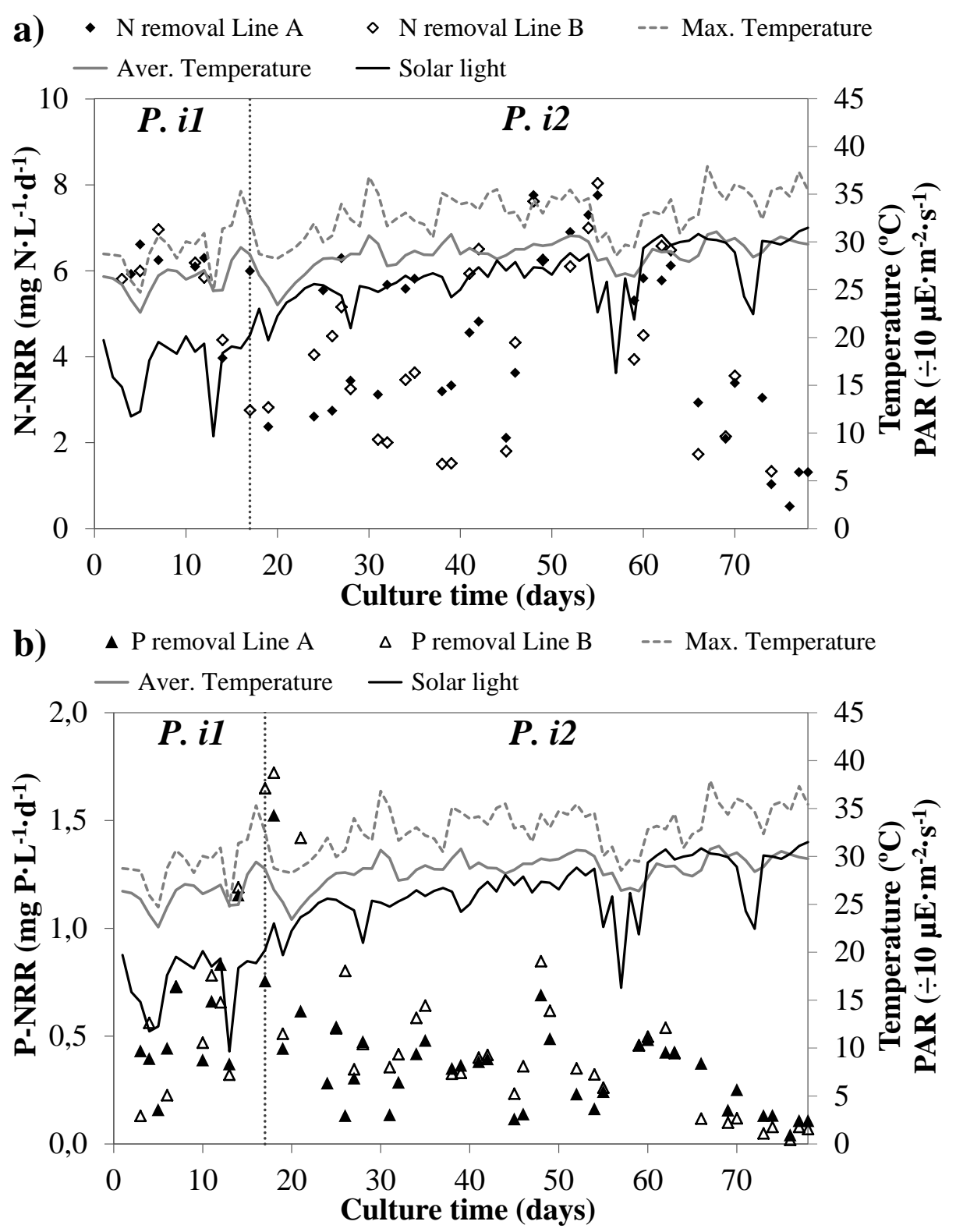

Figure 3: Time evolution of nutrient recovery obtained during period i: (a) NRR (nitrogen), temperature (average and maximum) and solar irradiance (PAR); and (b) NRR (phosphorus) temperature (average and maximum) and solar irradiance (PAR). The vertical line separates sub-period i1 and sub-period i2. 

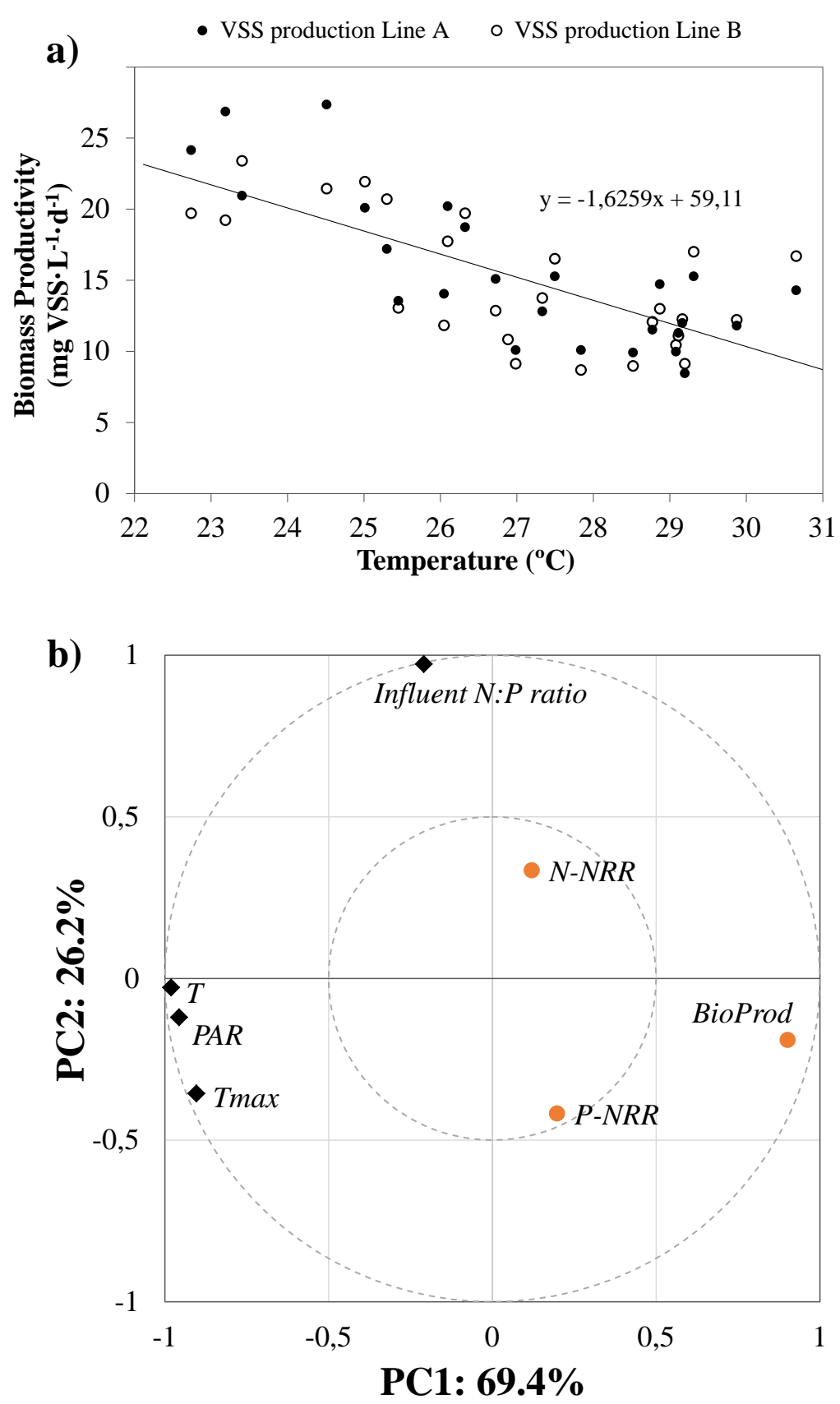

Figure 4: (a) Evolution of daily average VSS productivity versus daily average temperature during period i; and (b) PLSR results from period i: correlation circles plot from the integration of the selected predictors (Influent N:P, T, Tmax and PAR) and responses (BioProd, N-NRR and P-NRR). Nomenclature: PC: Principal Component; N:P: nitrogen to phosphorus ratio in the influent; T: daily average temperature; Tmax: daily maximum temperature; PAR: light intensity; BioProd: biomass productivity; N-NRR: nutrient recovery rate referred to nitrogen; and P-NRR: nutrient recovery rate referred to phosphorus. 


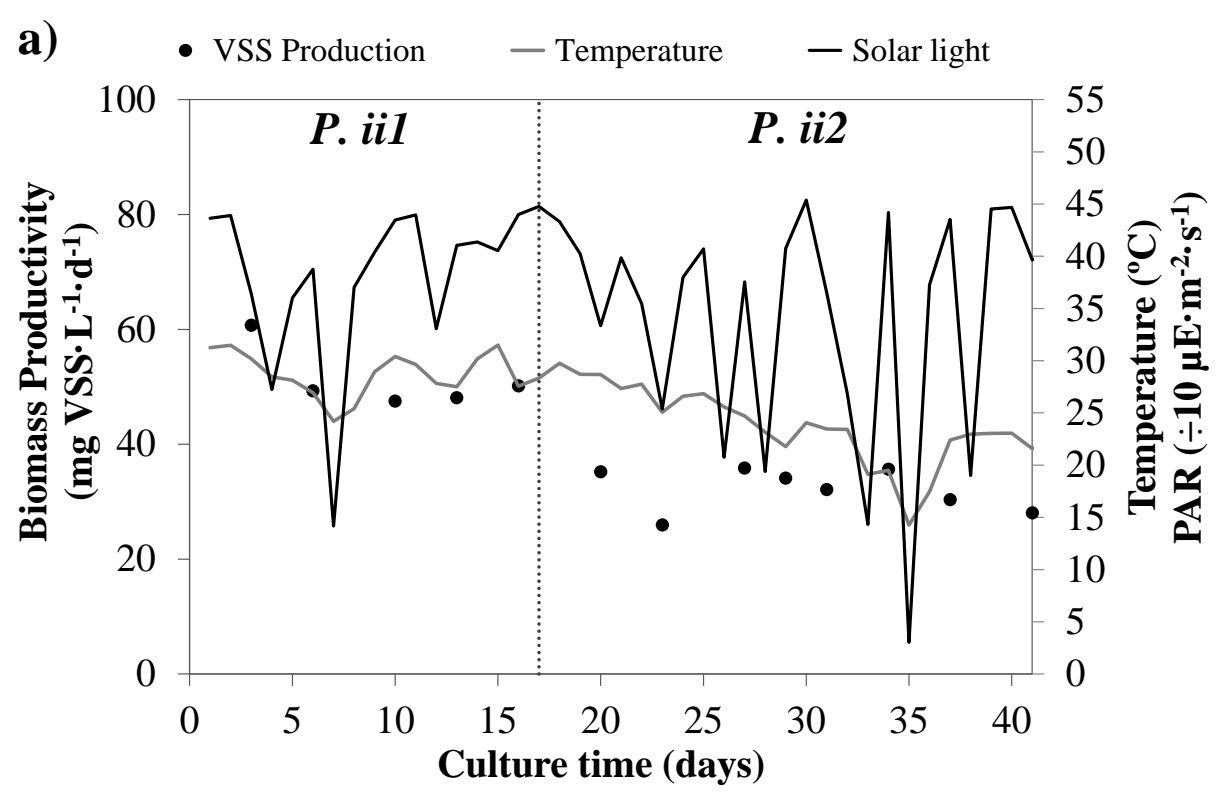

b) $\Delta \mathrm{N}$ removal rate $\Delta \mathrm{P}$ removal rate - Temperature - Solar light

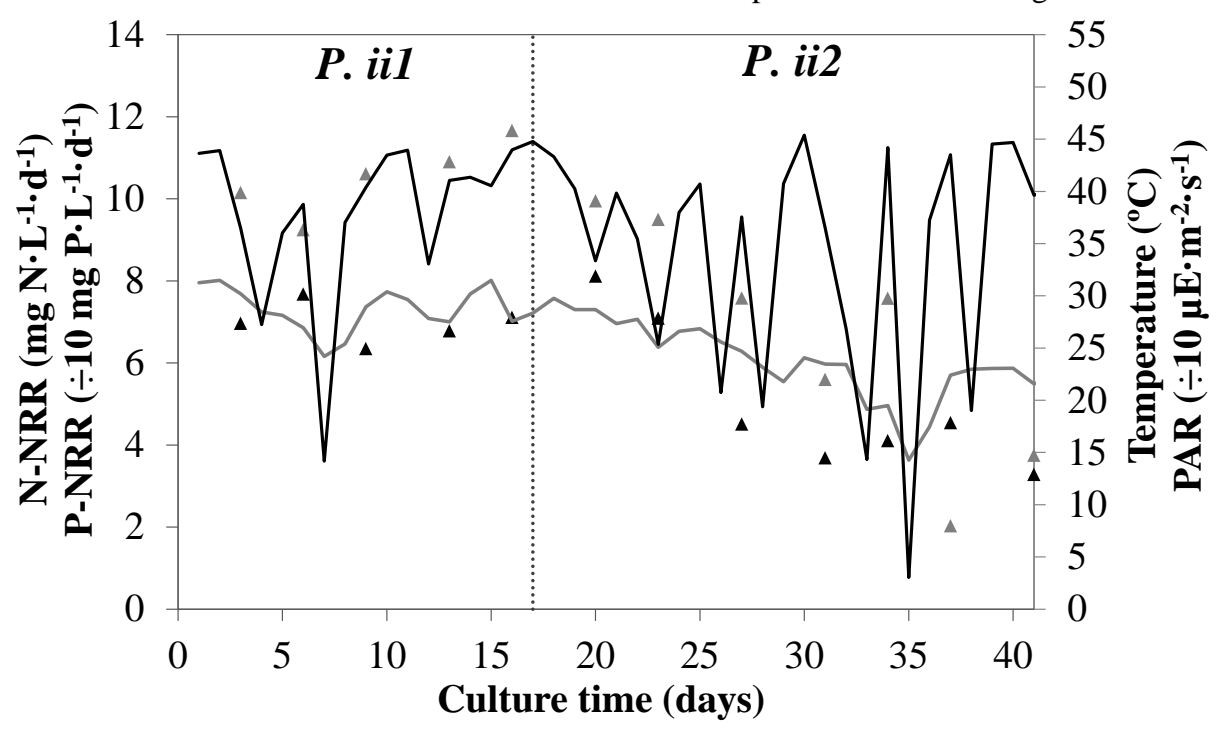

Figure 5: Time evolution of biomass productivity and nutrient recovery obtained during period ii: (a) VSS productivity, temperature and solar irradiance (PAR); and (b) NRR, temperature and solar irradiance (PAR). The vertical line separates sub-period ii1 and sub-period ii2. 


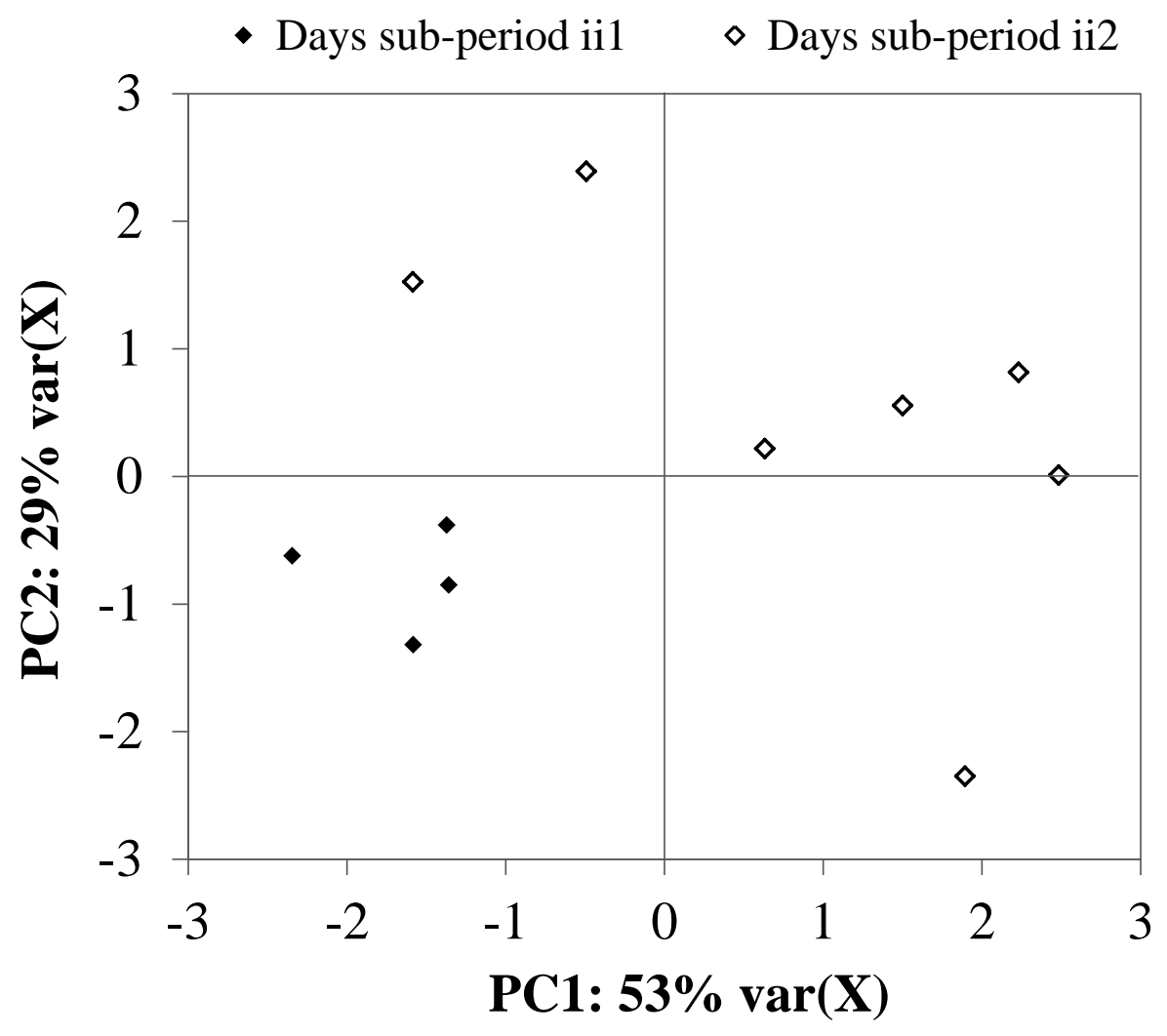

Figure 6: PLSR results from period ii: sample plot resulting from the principal component analysis of the 11 data sets from this period. 